Discussion Paper No. 08-106

\title{
Detection of
} Anticompetitive Horizontal Mergers

Kai Hüschelrath

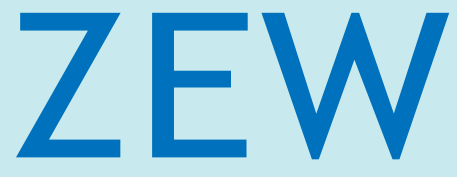

Zentrum für Europäische Wirtschaftsforschung $\mathrm{GmbH}$

Centre for European

Economic Research 


\title{
Discussion Paper No. 08-106 \\ Detection of Anticompetitive Horizontal Mergers
}

\begin{abstract}
Kai Hüschelrath
Download this ZEW Discussion Paper from our ftp server:

ftp://ftp.zew.de/pub/zew-docs/dp/dp08106.pdf
\end{abstract}

Die Discussion Papers dienen einer möglichst schnellen Verbreitung von neueren Forschungsarbeiten des ZEW. Die Beiträge liegen in alleiniger Verantwortung der Autoren und stellen nicht notwendigerweise die Meinung des ZEW dar.

Discussion Papers are intended to make results of ZEW research promptly available to other economists in order to encourage discussion and suggestions for revisions. The authors are solely responsible for the contents which do not necessarily represent the opinion of the ZEW. 


\section{Non-technical summary}

A key challenge in the work of a competition authority is the investigation of various business conducts with respect to their effects on market competition. In case of horizontal mergers, the authority typically has to investigate whether potential positive merger effects are likely outweighed by potential anticompetitive effects (such as price increases) triggered by the merger. Given this work description - and having in mind the fundamental resource and information constraints faced by the authority - a key ingredient of an efficient antitrust policy is the design (and implementation) of an appropriate investigation framework. For the authority, such a framework allows identifying (and prohibiting) the potentially most harmful mergers. For the companies, such a framework allows important (ex ante) presumptions whether a certain merger plan has a realistic chance to be given the green light by the authority.

Against this background, the paper develops a four-step framework to detect anticompetitive horizontal mergers. In the first step, an estimate of the impact of the merger on the market price needs to be derived. Subsequent, the second step of the framework has to assess whether such a predicted price increase would be sustainable postmerger. The third step needs to assess whether the identified efficiencies are substantial enough to at least hold the pre-merger price level. Finally, the fourth step has to consider the effects of a horizontal merger on other competition variables such as product variety, marketing as well as R\&D post-merger. 


\section{Nichttechnische Zusammenfassung}

Eine zentrale Herausforderung in der Arbeit einer Wettbewerbsbehörde liegt in der Untersuchung einer Vielzahl an unternehmerischen Verhaltensweisen in Märkten im Hinblick auf die dadurch ausgelösten Effekte auf den Wettbewerb. Im Falle von horizontalen Fusionen muss die Behörde typischerweise untersuchen, ob die positiven volkswirtschaftlichen Effekte eines Fusionsvorhabens nicht überragt werden von volkswirtschaftlich negativ einzuschätzenden Effekten wie beispielsweise Preiserhöhungen. Geht man von einer solchen Arbeitsbeschreibung einer Wettbewerbsbehörde aus und behält dabei die bestehenden Ressourcen- und Informationsknappheiten im Hinterkopf, so muss ein wesentlicher Bestandteil einer effizienten Wettbewerbspolitik in der Schaffung (und der Umsetzung) eines geeigneten Untersuchungsschemas gesehen werden. Der Wettbewerbsbehörde hilft die Anwendung eines solchen Schemas bei der Identifikation (und der anschließenden Untersagung) der volkswirtschaftlich schädlichsten Fusionen. Den Unternehmen erlaubt ein solches Schema eine Einschätzung darüber, ob ein bestimmtes Fusionsvorhaben eine realistische Chance hat, grünes Licht von der Wettbewerbsbehörde zu bekommen.

Vor diesem Hintergrund entwickelt das Arbeitspapier ein vierstufiges Untersuchungsschema zur Aufdeckung von wettbewerbsfeindlichen horizontalen Fusionen. In der ersten Stufe muss eine Abschätzung darüber erfolgen, welche Auswirkungen die Fusion auf den Marktpreis haben würde. In der zweiten Stufe des Schemas muss sich dann detaillierter mit der Frage befasst werden, ob die im ersten Schritt unter abstrakten Bedingungen abgeschätzte Preiserhöhung unter den gegebenen realen Marktbedingungen im Falle einer Fusion tatsächlich auftreten würde. In der dritten Stufe muss dann der Frage nachgegangen werden, ob möglicherweise durch die Fusion entstehende Effizienzvorteile einen Preisanstieg nach erfolgter Fusion verhindern würden. In der vierten Stufe sind schließlich die möglichen Effekte der Fusion auf andere Wettbewerbsparameter wie beispielsweise Produktvielfalt, Marketing oder F\&E genauer zu untersuchen. 


\title{
DETECTION OF ANTICOMPETITIVE HORIZONTAL MERGERS
}

\author{
Kai Hüschelrath \\ Centre for European Economic Research (ZEW) \\ Department of Industrial Economics \\ and International Management \\ L 7, 1 - 68161 Mannheim - Germany \\ Phone: $+49 / 621 / 1235-384$ \\ Fax: +49/621/1235-170 \\ E-mail: hueschelrath@zew.de
}

\begin{abstract}
The paper develops a four-step framework to detect anticompetitive horizontal mergers. In the first step, an estimate of the impact of the merger on the market price needs to be derived. Subsequent, the second step of the framework has to assess whether such a predicted price increase would be sustainable post-merger. The third step needs to assess whether the identified efficiencies are substantial enough to at least hold the premerger price level. Finally, the fourth step has to consider the effects of a horizontal merger on other competition variables such as product variety, marketing as well as R\&D post-merger.
\end{abstract}

Keywords Competition policy, antitrust enforcement, mergers, unilateral effects

JEL Class L40, L41, K21 
Introduction

The detection of anticompetitive mergers is a multidimensional problem. First and foremost, a horizontal merger inevitably leads to the loss of a direct competitor in a market and is therefore suspicious of leading to price increases. From an economic perspective, there are basically two strands of argument which both explain such post-merger price increases. On the one hand, the merged entity unilaterally might have incentives to decrease output and increase price given an increase in market power post-merger. Although the non-merging firms in the industry typically respond to such a move with an increase in output, Farrell and Shapiro (1990) have shown that the former effect is typically stronger than the latter leading to an increase in price and a corresponding reduction in consumer surplus. On the other hand, post-merger prices may be higher than pre-merger prices because the firms in the post-merger market find it easier to collude tacitly or overtly. These effects are covered by the so-called coordinated effects analysis, which is not considered further below. ${ }^{1}$ In addition to the effect on price, horizontal mergers may influence welfare through several other channels, such as especially merger-specific efficiencies, product repositioning, product variety and the incentives to innovate. ${ }^{2}$

\section{Direct detection of anticompetitive horizontal mergers}

Given these problem specifications and having in mind the possibilities to actively detect cartels (by identifying asymmetric shocks or structural breaks) discussed in the recent literature (see Hüschelrath (2008) for an overview), the question arises whether comparable markers are available who can detect anticompetitive mergers. Based on the seminal work of Eckbo (1983), Eckbo and Wier (1985) and Stillman (1983), the event-study approach may provide such a possibility. The simple idea behind such a study is that a merger that will increase market power of the merging firms is also 'pleasant' for the rival firms in the market. If, however, the merger creates significant efficiencies and provides an incentive for the merged entity to lower prices post-merger, that can be considered as 'unpleasant' for the rival firms in the market. As a consequence, analysing the stock-price reactions of the rival firms to the announcement of a merger proposal can be helpful in distinguishing between mergers motivated by increases in market power (positive price reaction of rivals' stocks) and mergers motivated by the realisation of efficiencies (negative price reaction of rivals' stocks). The respective hypotheses are outlined in Table 1.

1 The theory of coordinated effects is largely based on the theory of repeated games and basically uses the same screens as in hard core cartel detection (see Kaplow and Shapiro, 2007: 71ff., for a short overview). Essentially, unilateral and coordinated effects theories aim at investigating the potentials for price increases post-merger. While the unilateral effects assessment basically focuses on the possibilities of the merged entity to increase price, the coordinated effects assessment focuses on the increased possibilities of all firms or a group of firms to overtly or tacitly collude post-merger, thereby increasing the post-merger market price.

2 As noted by Kaplow and Shapiro (2007), a price increase can also serve as a proxy for other possible anticompetitive effects, such as a reduction in product quality or service or a decrease in the pace of innovation. 
Table 1. Abnormal returns to the merging firms and their rivals

\begin{tabular}{|c|c|c|}
\hline & $\begin{array}{l}\text { Abnormal returns to } \\
\text { merging firms }\end{array}$ & $\begin{array}{c}\text { Abnormal returns to } \\
\text { rival firms }\end{array}$ \\
\hline \multicolumn{3}{|l|}{ A. Merger proposal } \\
\hline Market power: & Positive & Positive \\
\hline Collusion or Cournot & (Monopoly rents) & (Monopoly rents) \\
\hline Economic efficiency: & Positive & Negative \\
\hline Productivity increases & (Cost savings) & (Competitive disadvantage) \\
\hline \multicolumn{3}{|l|}{ B. Antitrust complaint } \\
\hline Market power: & Negative & Negative \\
\hline Collusion or Cournot & (Loss of monopoly rents) & (Loss of monopoly rents) \\
\hline Economic efficiency: & Negative & Positive \\
\hline Productivity increases & (Loss of cost savings) & $\begin{array}{c}\text { (Avoiding competitive } \\
\text { disadvantage) }\end{array}$ \\
\hline
\end{tabular}

Source: Content follows Eckbo and Wier (1985: 124)

As shown in Table 1, in addition to focusing on rivals' stock price reactions at the time of the announcement of the merger, the reactions to the announcement of an antitrust complaint may disclose additional evidence on the pro- or anticompetitiveness of the respective merger.

Although the event-study method looks like a relatively easy way to detect anticompetitive mergers - and several empirical studies have shown that they can indeed be helpful for the detection of anticompetitive mergers - the concept has to cope with substantial drawbacks. First of all, the event study approach is only applicable for firms with publicly traded shares. This precondition may already exclude many acquisitions of small- and medium-sized firms from an event-study analysis. ${ }^{3}$ Furthermore, as argued by McAfee and Williams (1988: 199ff.), firms often derive only a small fraction of their revenues from the markets affected by the merger, and consequently the power of event studies to detect anticompetitive mergers is rather limited. A test of the event study approach with a known anticompetitive merger ${ }^{4}$ showed that the event study approach would have failed to detect that merger (see McAfee and Williams, 1988. 200ff.). Whinston (2006: 111) discusses 'precedent effects' as another potential pitfall of event studies. He argues that the announcement of a merger may convey information about market conditions more generally - such as the likelihood of further mergers as a reaction to the announcement of an efficiency-enhancing merger in the industry - and therefore may lead to "diametric" stock price reactions, such as increases in rivals' stock prices following the announcement of an efficiency-enhancing merger.

\section{Indirect detection of anticompetitive horizontal mergers}

Given the substantial problems in the application of the event study approach, the development of an indirect but generally applicable framework to detect anticompetitive mergers is necessary. The following four-step approach is proposed to guide such an analysis:

3 A counterargument could be that these mergers are typically unproblematic from an antitrust perspective and consequentially do not create a need to conduct an event study anyway.

$4 \quad$ McAfee and Williams (1988) use the 1979 merger of Xidex Corporation with Kalvar Corporation. Both firms produced non-silver duplicate microfilms. Post-merger, Xidex closed down the production facility of Kalvar, fired all employees and raised prices substantially for their own remaining products. 
1. Estimation of the post-merger price increase

2. Consideration of evidence whether such a price increase would be sustainable

3. Estimation of the effect of possible merger efficiencies on the post-merger price

4. Consideration of the effects of the merger on competition variables other than price (such as product variety or the incentives to innovate).

The first step of the framework needs to develop an estimate of the impact of a horizontal merger on the market price(s). Such an estimate can be achieved either by applying econometric techniques or by applying simulation techniques based on theoretical models.

The second step of the framework has to assess whether the price increase predicted in the first stage would be sustainable post-merger. As econometric and simulation tools typically need to abstract from important factors - such as entry or product-repositioning of existing rivals - these factors have to be assessed quantitatively (or at least qualitatively) with a conclusion whether these factors make it likely or unlikely that the merged entity would be able to actually impose the estimated price increase post-merger.

The third step of the framework needs to assess, first, whether the merger efficiencies claimed by the merging parties are existent, merger-specific and likely to materialise postmerger. Second, it needs to estimate whether the accepted efficiencies are strong enough at least hold to the pre-merger price level.

The fourth step of the framework needs to consider the effects of a horizontal merger on other competition variables such as product variety, marketing and R\&D post-merger, which might influence the overall welfare effects of a merger.

The four-step approach will be applied next to horizontal mergers for two types of models: a homogenous Cournot model and a differentiated Bertrand model. Generally, standard Cournot models are a good approximation in homogenous good industries in which competition is accurately modelled by a (one-shot) quantity-setting game - or alternatively as a capacity-setting game with subsequent price competition (see Kreps and Scheinkman, 1983). If, however, a horizontal merger in a differentiated branded-products market has to be assessed, a differentiated Bertrand model typically delivers the better approximation of competitive interaction (see Kaplow and Shapiro, 2007: 59ff.).

\subsection{Estimation of the post-merger price increase}

The first step of the framework assesses the standard competitive concern raised by most horizontal mergers: their potential to increase prices post-merger. Based on a specification of pre-merger market conditions and assumptions on the behaviour of firms in the market, economic models can be applied to estimate post-merger price increases (see Epstein and Rubinfeld, 2001: 886ff., for a detailed description).

Starting with an assessment in a homogenous market in which market interaction is best described by quantity competition, Dansby and Willig (1979) derive the following simple relationship between the Lerner index of market power and the Herfindahl-Hirschman Index:

$$
L=\sum_{i} \frac{m_{i}^{2}}{\varepsilon_{D}^{m}}=\frac{H H I}{\varepsilon_{D}^{m}} .
$$

Equation (1) shows that the Lerner index for an industry is given by its HHI divided by the market demand elasticity. Market power is increasing with the concentration in a market and decreasing with the market demand elasticity. In order to receive a simple, back-of-the-envelope estimate of the price increase following a horizontal merger, 
Equation (1) can be rearranged to receive the following expression for the price increase following a horizontal merger (see Annex 7.1 for the proof):

$$
\frac{\Delta p}{p}=\frac{\Delta H H I}{\varepsilon_{D}^{m}-H H I_{\text {postmerger }}} .
$$

As shown by Equation (2), the percentage price increase following a merger is given by the change in the HHI divided by the market demand elasticity minus the HHI in the postmerger state. Alternatively, Equation (2) can be expressed in market shares

$$
\frac{\Delta p}{p}=\frac{\Delta H H I}{\varepsilon_{D}^{m}-H H I_{\text {postmerger }}}=\frac{2 s_{1} s_{2}}{\varepsilon_{D}^{m}-\left(\sum_{i}\left(s_{i}\right)^{2}+2 s_{1} s_{2}\right)}
$$

with $s_{1}$ and $s_{2}$ indicating the market shares of the merging companies. Figure 1 plots Equation (2) based on unity market demand elasticity.

Fig. 1. Percentage price increase due to a merger in a homogenous Cournot model

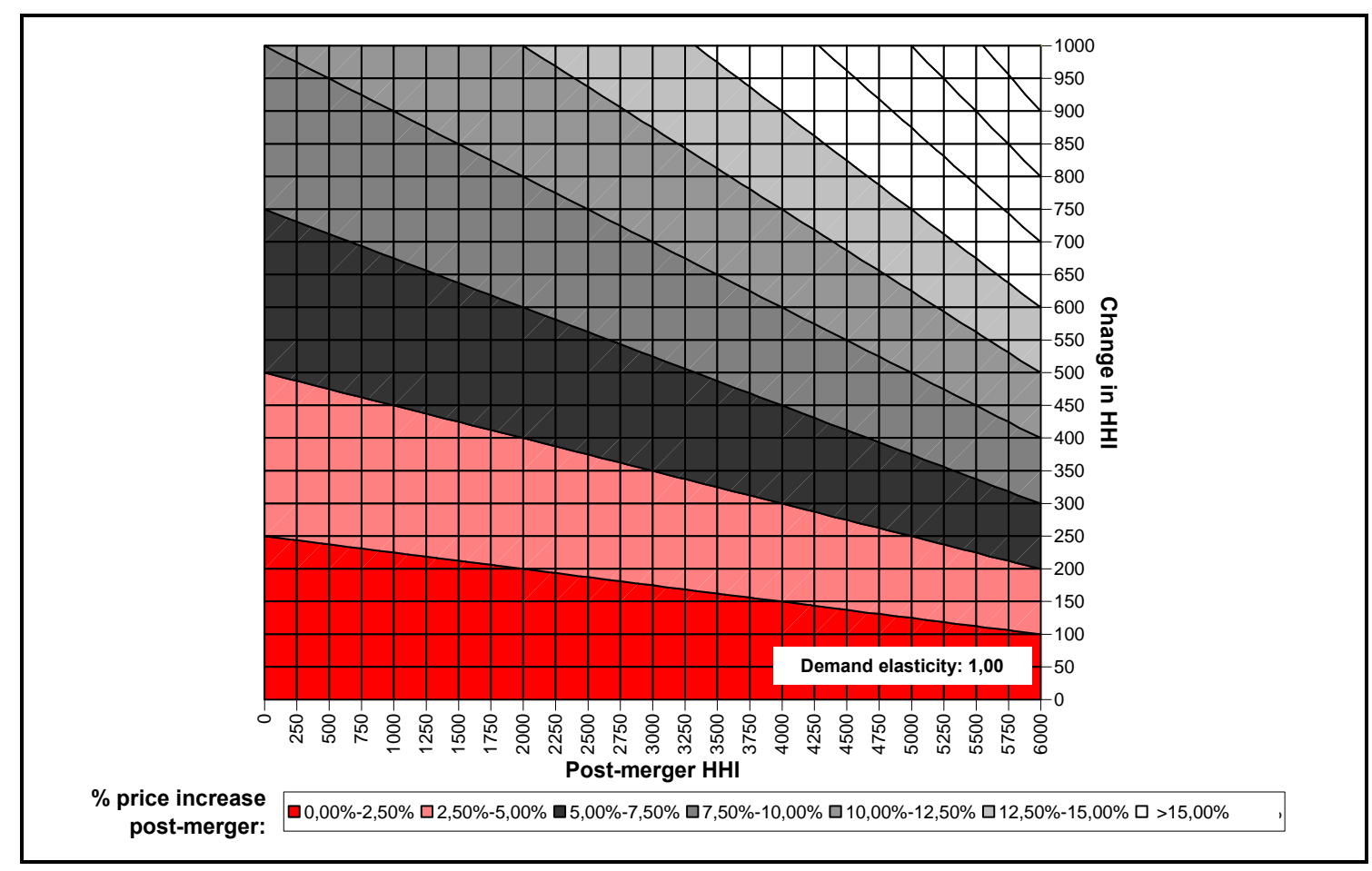

Figure 1 shows the percentage price increase post-merger for various combinations of post-merger HHI and the merger-induced change of the HHI. For example, a post-merger HHI of 3000 and a corresponding change in the HHI of 450 would forecast a price increase between 5,00\%-7,50\% (the exact value is 6,43\%). However, for a demand elasticity of 1,5 , the predicted price increase would drop to $3,75 \%$. This example already indicates the sensitivity of the results with respect to the underlying market demand elasticity, which will be studied further below.

Furthermore, as assessed in more detail in Nelson and Sun (2001: 935ff.), Equation (2) and the corresponding Figure 1 are based on several assumptions which might become critical in the sense that they are not met in the market being investigated. Apart from 
obvious assumptions such as (1) quantity competition or (2) the presence of homogenous goods, other less obvious but nevertheless potentially critical assumptions include that (3) all firms are assumed to have constant marginal costs, (4) the merger does not change the cost structure of the firm, (5) the merger does not change the behaviour of the firms, (6) the post-merger market share of the firms is equal to the sum of their pre-merger market shares, (7) the elasticity of demand is constant over the relevant range of sales levels and (8) there is no entry. Werden and Froeb (2007: 7) consider assumptions (3) and (6) as especially critical, which reduces the significance of price-increase estimates derived by the above formula. Merger simulations - as sketched below for a differentiated products market - can typically help to relax at least some of the critical assumptions of simple, back-of-theenvelope formulas.

In a world of differentiated branded products, a Bertrand model is typically an appropriate approximation of competitive interaction. In general, product differentiation lessens competition, as an increase in price by one firm does not immediately lead to the loss of all customers for that firm. ${ }^{5}$ The basic reason for this finding - first reflected in the theory of monopolistic competition by Chamberlin (1933) as well as the theory of imperfect competition by Robinson (1933) - is that products are not perfect substitutes for each other any more, with the direct effect that a fraction of customers would still buy the product in the event of a price increase. The first chart in Figure 2 below explains this fundamental characteristic of differentiated product markets. ${ }^{6}$

Figure 2 shows four products (A, B, C and D) which are located at different places among a line representing consumer preferences. In the initial stage, it is assumed that the prices for all products are the same. The substitutability between different products (from the consumer perspective) is expressed by the slope of the umbrellas originating in the respective basis product prices. Given this set-up, Chart 1 in Figure 2 shows the consequences of a price rise of firm $\mathrm{C}$ from $\mathrm{Pc}$ to $\mathrm{Pc}^{\prime}$. Although company $\mathrm{C}$ would loose all customers located in the areas cd-c'd and bc-bc' to products D and B, it would still keep the customers between $c^{\prime} d$ and $b^{\prime}$. Dependent on the exact market specifics, company $C$ will trade off the margin increase of the remaining customers with the loss in customers to decide whether a price increase is profitable or not. ${ }^{7}$

Now imagine that the producers of products $\mathrm{B}$ and $\mathrm{C}$ in Figure 2 consider merging. In such a case, the second chart in Figure 2 shows that it becomes - ceteris paribus - more likely that the price increase for products $\mathrm{B}$ and $\mathrm{C}$ (the merged entity) is profitable, as the customers switching from product $\mathrm{B}$ to product $\mathrm{C}$ are not lost for the merged entity but just have to pay the higher price (see Willig, 1991, for a detailed assessment). In other words, an evaluation of mergers in differentiated product markets needs to assess not only how many customers a firm would loose following a price rise but also whom these customers switch to. The so-called diversion ratio satisfies this demand.

5 While horizontal differentiation leads to different features of products (valued by the consumers), vertical differentiation relates to differences in quality levels (of the same features).

$6 \quad$ Inspired by comparable graphs in Bishop and Walker (2002: 71) and Baker and Bresnahan (1985: 429). Although the aim of Figure 2 is purely presentational, without having in mind any specific model, the general set-up is equal to a typical Hotelling location model with Bertrand competition. D'Aspremont et al. (1979) show that as long as the (two) firms can change their prices and location costless, no equilibrium exists in such a model. However, modifications of the model can prove the existence of an equilibrium (see Carton and Perloff, 2000: 217ff.).

7 Although Figure 2 assumes that the horizontal 0-1 line represents the spectrum of customer preferences, it is also possible to interpret the horizontal 0-1 line in a spatial sense. The umbrellas would then mirror the transportation costs, which determine the intensity of competition between different locations. In other words, the graph can refer to both types of differentiated products: branded consumer products and physical facilities that distribute goods where differentiation is based on location, such as supermarkets or hospitals (see Shapiro, 1995: 2f.). 
Fig. 2. Competition between horizontally differentiated products

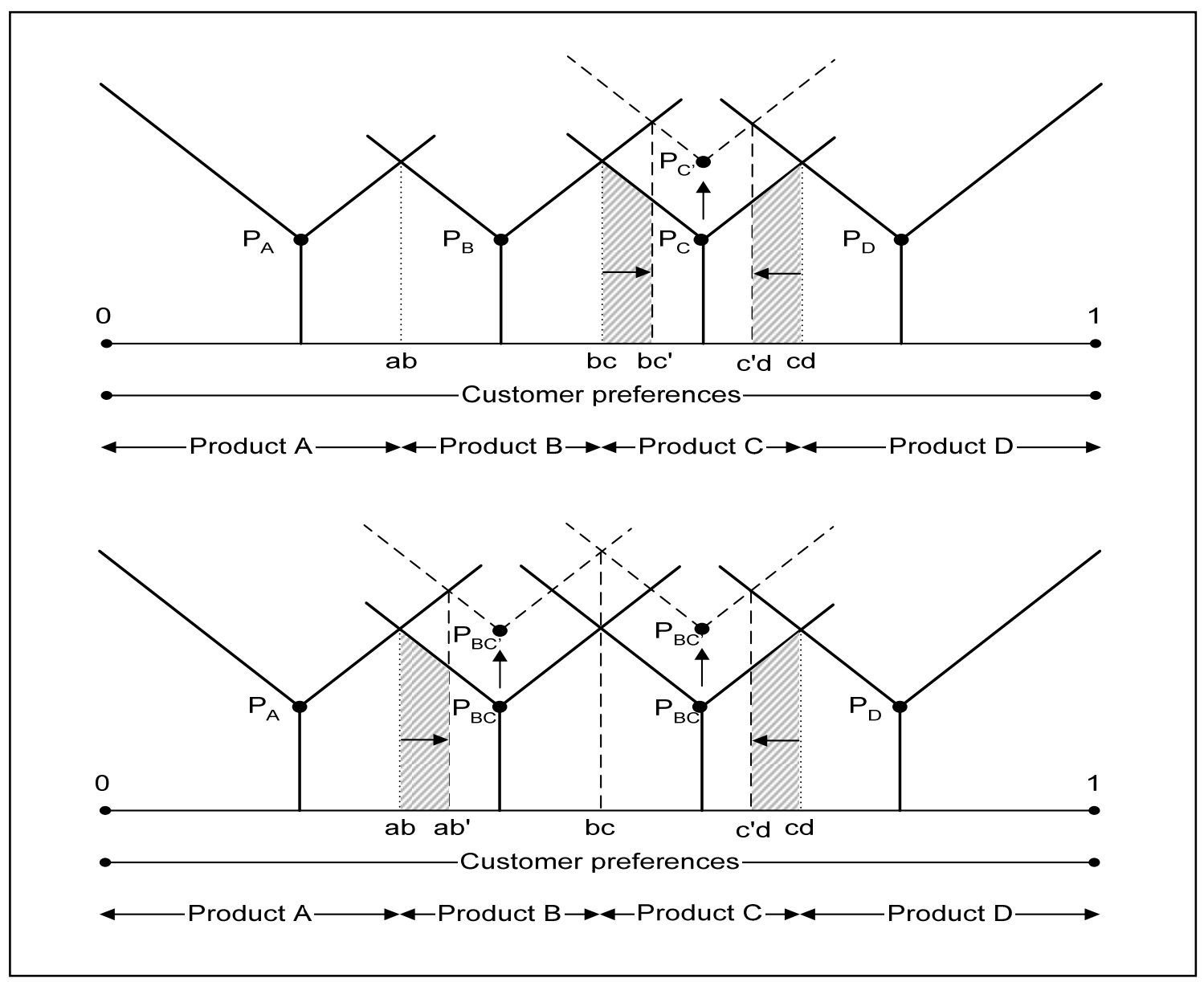

The diversion ratio is a measure of how close two products are in the product space and therefore how intense competition is between these two products. Shapiro (1996) defines the diversion ratio as "the fraction of sales lost by brand $[\mathrm{C}]$ that are captured by brand $\mathrm{B}$ in case the price for brand $[\mathrm{C}]$ is increased by a certain percentage rate." ${ }^{8}$ Table 2 explains the concept in a hypothetical four-product market.

Table 2. Calculating diversion ratios

\begin{tabular}{lcccc}
\hline & $\begin{array}{c}\text { Initial Sales } \\
\text { (volume) }\end{array}$ & $\begin{array}{c}\text { Sales after 5\% } \\
\text { price rise of C }\end{array}$ & $\begin{array}{c}\text { Diversion in } \\
\text { volume }\end{array}$ & Diversion ratio \\
\hline Brand A & 5000 & 5000 & 0 & 0,0 \\
Brand B & 3500 & 3900 & 400 & 0,4 \\
Brand C & 2000 & 1000 & -1000 & 0,6 \\
Brand D & 1000 & 1600 & 600 & 1,0 \\
Total & 11500 & 11500 & 0 & 5 \\
\hline
\end{tabular}

As shown in Table 2 , it is assumed that the price for product $\mathrm{C}$ is raised by $5 \%$, which leads to a reduction in its sales of 50\% (i.e., 1000 units). Then 600 units of the 1000 units in sales switch to product $\mathrm{D}$, while the remaining 400 units switch to product $\mathrm{B}$, leading to diversion ratios of 0,6 for products $\mathrm{C}$ and $\mathrm{D}$ and 0,4 for products $\mathrm{C}$ and $\mathrm{B}$. Product $\mathrm{A}$ does

8 Technically, the diversion ratio from A to B is the ratio of the cross-price elasticity of demand for A with respect to the price of $\mathrm{B}$ over the own elasticity of demand for $\mathrm{A}$. In a logit model, the market diversion ratio between products 1 and 2 is given by the market share of product 2 divided by 1 minus the market share of product 1. 
not gain any additional sales from the price increase of product $C$, leading to a diversion ratio of 0,0 between product $C$ and $A$. If, however, products $B$ and $C$ belong to one firm, a price increase in product $\mathrm{B}$ lead to a loss of some customers to product $\mathrm{A}$, but the loss to product $\mathrm{C}$ stays within the firm. Hence the loss of revenue is less and price rises are more likely to be profitable. As a consequence, firms which control a larger product portfolio (i.e., have a high market share) will charge higher prices than firms with a smaller product portfolio.

A very helpful characteristic of diversion ratios is that they can be incorporated into a differentiated Bertrand model to derive an estimate of the post-merger price increase in a differentiated products industry. As shown in Annex 7.2, if the demand function is linear, the percentage price increase triggered by the merger can be derived by the following expression:

$$
\frac{\left(P^{\text {Post-Merger }}-P^{\text {Pr } e-\text { Merger }}\right)}{P^{\text {Pr } e-\text { Merger }}}=\frac{M D}{2(1-D)} .
$$

Equation (4) basically shows that the post-merger price increase is a function of the premerger price-cost margin as well as the diversion ratio between the two brands merging. Generally, higher margins result from greater product differentiation, while a higher diversion ratio, as explained above, reflects more intense competition between the products (see Werden, 1996). Plotting Equation (4) for various combinations of pre-merger pricecost margin and diversion ratios leads to Figure 3.

Fig. 3. Percentage post-merger price increases against pre-merger price-cost margin and diversion ratio

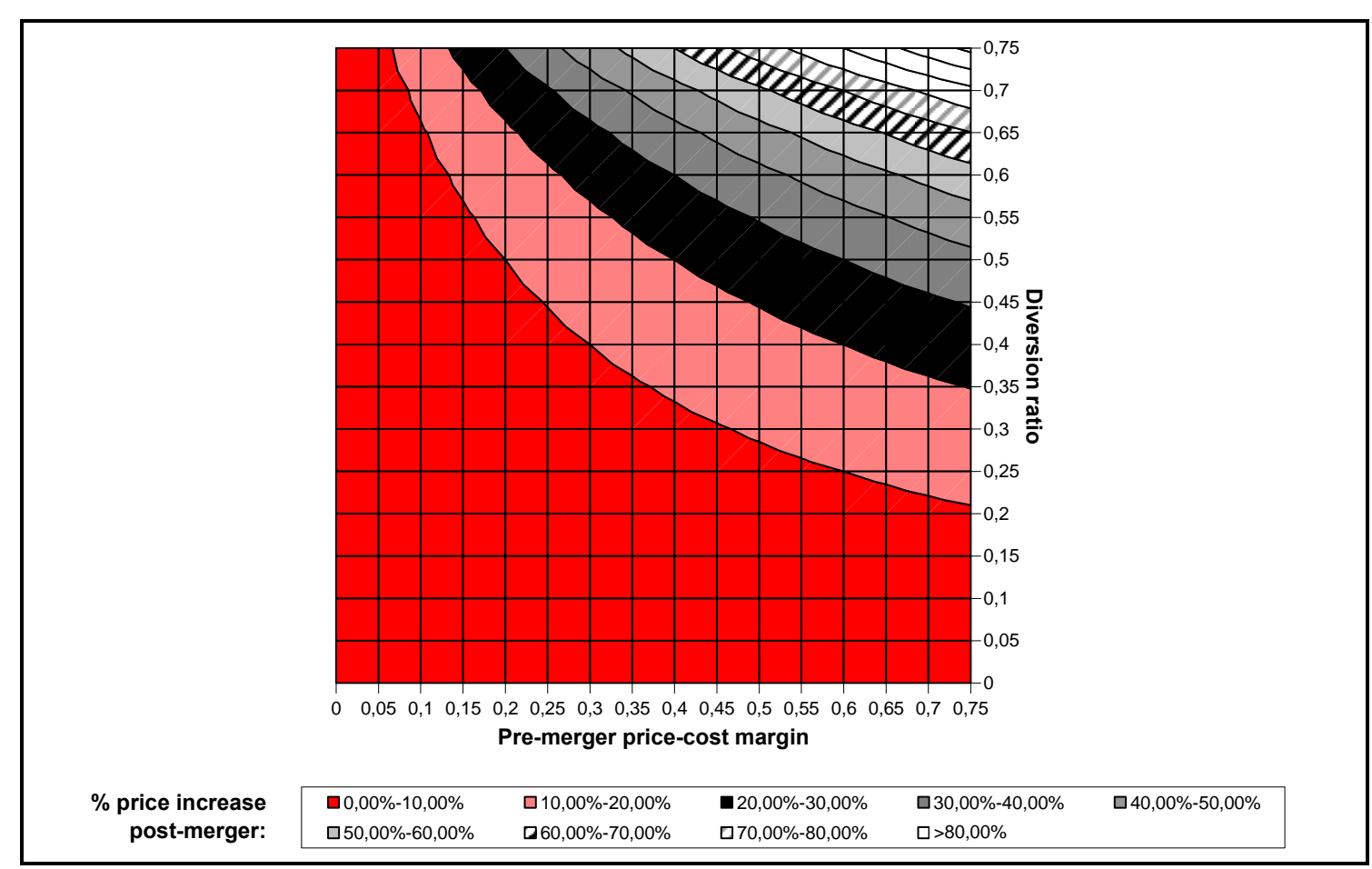

As shown in Figure 3, for diversion ratios below 0,2, the percentage price increase postmerger is estimated to be below $10 \%$ (the exact value for $\mathrm{M}=0,4$ and $\mathrm{D}=0,2$, e.g., is $5,00 \%)$. Generally, the percentage price increase post-merger rises with the pre-merger 
price-cost margin and the diversion ratio. This is in line with the general interpretation of the diversion ratio provided above.

However, it is important to remark that Equation (4) is only valid as long as the two merging firms are identical before the merger, they both produce a single product premerger and both face a linear demand curve. As argued by Bishop and Walker (2002: 374), all three assumptions can be critical, leading to wrong conclusions if Equation (4) is just applied mechanically without studying the suitability of the underlying assumptions up front. As shown in Annex 7.2, if the demand curve is assumed to be iso-elastic instead of linear, Equation (4) changes to

$$
\frac{\left(P^{\text {Post-Merger }}-P^{\text {Pr } e-\text { Merger }}\right)}{P^{\text {Pr } e-\text { Merger }}}=\frac{M D}{(1-M-D)}
$$

leading to significant changes in the price predictions as well as the range of economically interpretable results. ${ }^{9}$ Furthermore, if the assumption of symmetric firms is released, then the respective equation to estimate the price increase loses some of its applicability charme' (see Bishop and Walker, 2002: 378f.).

On a more general level, Hausman and Leonard (1997) fundamentally criticise the use of such back-of-the-envelope formulas. Following the 'some-number-is-better-than-nonumber' fallacy discussed in Diamond and Hausman (1994), they argue that it would be preferable to rely entirely on qualitative analysis - in case the data (and/or time) for a sophisticated estimation of a demand model (see Hausman et al., 1994, for an overview) is not available - rather than applying simple simulation techniques such as diversion ratio analysis. Werden (2004b: 4), however, takes the counterargument by remarking that "priceincrease predictions are only rough estimates, but that is better than none at all'.

In line with the reasoning in Werden (2004b), diversion ratios and corresponding estimates of post-merger price increases can provide useful back-of-the-envelope results for differentiated product mergers in which a) market interaction is adequately described by Bertrand competition, b) the mentioned assumptions are met to an acceptable degree, and c) the existing data and the budget or skills in the antitrust authority do not allow a more sophisticated analysis, such as the estimation of demand systems ${ }^{10}$ (see Hausman et al., 1994, for an overview). In any case, such simple simulation results - as well as the results of more sophisticated techniques - should be viewed as one piece of evidence and should by no means replace a qualitative assessment of the case based on documents, interviews with customers and institutional details. ${ }^{11}$

As an alternative to the application of back-of-the-envelope formulas, economists have developed more sophisticated 'merger simulation tools' to come to conclusions on the likely effects of a horizontal merger on market price (see Werden and Froeb, 2007: $31 \mathrm{ff}$. and ABA, 2005: 269ff. for more detailed overviews). In general, these tools use a model of consumer demand and a model of competitive interaction to predict the price effects of a merger (see Hausman and Leonard, 1997). In order to be able to apply such tools, market information, such as market shares and market demand elasticities, needs to be estimated as data input for the simulation of the effect of a merger-induced change in the ownership structure on market price.

$9 \quad$ As $(1-\mathrm{M}-\mathrm{D})>0$, D must be larger than (1-M) to deliver interpretable economic results (which delineates a relatively small range of sensible price predictions).

10 Scanner data from supermarkets is an example of 'good data' which technically allows the application of more sophisticated approaches. However, time limitations or missing skills in the technicalities of such forms of analysis may hinder its application on the side of the antitrust authority.

11 Although merger simulation focuses on a quantification of the unilateral effects of a merger, Davis (2006) provides an application focusing on coordinated effects. 
An especially helpful feature of merger simulation tools is that they allow simulating not only the post-merger prices but can also take account of changes in the cost structure (the so-called merger efficiencies) and antitrust-induced changes in the ownership structure (the so-called structural merger remedies). However, despite an increasing adoption of merger simulation tools in antitrust authorities and economic consultancies, the general suitability of such techniques is questioned by academics and practioners. Walker (2005: 27), for example, remarks that "merger simulation models do not allow investigators to avoid much of the competitive effects analysis relating to the relevant economic market, nor do they necessarily provide more precision to merger control." $\mathrm{He}$ adds that problems are predestined if 'off-the-shelf models' are applied for a certain case rather than 'bespoke models', which take account of relevant specifics of the market and industry at hand. ${ }^{12}$ Werden and Froeb (2007: 58) show, with data collected for a competitive effects assessment of the WorldCom-Sprint merger in the United States, that the estimated price increases post-merger heavily depend on the underlying demand form. With linear demand, the merger simulation led to a price increase of $2,3 \%$, while an iso-elastic demand would lead to an estimate of $16,4 \%$. However, in case of AIDS, an estimate of 13,8\% was obtained. This simple practical example underpins the general sensitivity of these models and the importance of getting the model input (such as the demand form) right in order to receive meaningful estimates of the post-merger price increase. This caveat is confirmed by Whinston (2006: 101f.), who identifies the following important caveats of merger simulation: 1.) The quality of the predictions depends on the correct estimation of demand; 2.) The choice of the post-merger behavioural model of the industry is key, as firm's may change their behaviour as a result of the merger; and 3.) Pricing is only one of several important competition variables such as entry or $\mathrm{R} \& \mathrm{D}$, and merger simulation tools so far have failed to include them.

Given the potential problems of merger simulations, Carlton (2003a: 7ff.) views these tools as a useful substitute for the more direct 'traditional' approaches for merger analysis, which basically build on 'natural experiments' aiming at answering the question "What happens to price when the number of competitors diminishes by one?" Carlton (2003a: 11) himself provides an example of such a natural experiment: "[S] uppose that there are 5 firms in most areas of the country, but only 4 in one area. Well, the difference in price between the two areas may be a good predictor of the effect of a merger if the regions are otherwise similar. By identifying such 'natural experiments', one can try to assess the effect on price of having one less firm. This type of analysis is called 'reduced' form analysis, in contrast to structural [such as merger simulation] because unlike structural analysis, the reason for the observed relationship between price and number of firms (e.g., the presence of demand substitutes) is not spelled out." Generally, the evidence created by such natural experiments is extensively used by economic consultancies in their merger assessments.

\subsection{Consideration of evidence whether such a price increase would be sustainable}

The second step of the detection framework for anticompetitive mergers is entered by cases which are suspicious of significantly increasing market prices post-merger. As

12 Slade (2006: 21) also criticises simple merger simulation tools because "the predictions about markups and merger effects that can be obtained from simple models are often very misleading. Unfortunately, however, a number of economists have attempted to convince competition authorities that user-friendly canned programs can provide reasonable predictions." However, later on, Slade agrees that back-of-theenvelope calculations can be useful "as long as everyone understands the assumptions that underlie those calculations and no spurious claims of accuracy are made ... However, we should eschew generic, one-size-fits-all merger models and numbers that come out of black boxes" (Slade, 2006: 23). 
simulation tools typically abstract from important factors - such as the potential role of entry or product repositioning of existing competitors - these factors have to be assessed qualitatively and have to be incorporated into a conclusion whether the estimated price increase would actually materialise in the post-merger world. ${ }^{13}$

A second focus of an assessment on the sustainability of a simulated price increase could be buyer power. In general, the existence of a significant countervailing power of customers typically reduces the ability of the merging parties to increase price post-merger. "Empirical studies have shown that the stronger and more concentrated the buyers' side of the market is, the less is any ability of sellers to elevate their prices"14 (ABA, 2005: 29). One central explanation for this finding is that collusion becomes harder to sustain because, on the one hand, deviation incentives are larger and, on the other hand, the buyers typically have incentives to monitor the transactions closely and are typically in a good position to question price increases (or might even use competitive bidding procedures to promote competition). Furthermore, large buyers often also have the possibility to sponsor entry into the supplier's market in order to increase competitive pressures (see ABA, 2005: 29).

A central focus of such an investigation lies on the role of entry barriers in the respective market, because even in the case that a merger simulation predicts a significant price increase post-merger, low-entry barriers in the respective market would likely make such a price increase unsustainable. Following the theory of contestable markets, even a monopolist has no choice other than to price at marginal cost if 'hit-and-run' entrants are waiting to enter the market as soon as it raises the price above competitive levels.

Even if market concentration is relatively high, incumbents may be unable to exercise market power (i.e., earning monopoly profits) as long as potential entrants could easily and quickly start producing substitutes. Consequently, an analysis of the likelihood, timeliness and sufficiency of entry following a price increase is a key component in assessing market power (see Waterson, 1981; Coate and Langenfeld, 1993; McAfee et al., 2004, for surveys). Furthermore, the analysis of (potential) entry usually plays an important role in the subsequent assessments of competitive effects of certain suspicious conducts as well as in the design of remedies.

The likelibood of entry is determined by the profitability and possibility of entry. The profitability of entry can be operationalised by estimating the expected net present value of the post-entry profits as well as the sunk costs of entry. ${ }^{15}$ If the discounted profits are larger than the sunk costs of entry, then entry would be profitable; otherwise it would not be (see e.g., Ross (2004) for a formal treatment). Whether entry would actually take place, however, does not only depend on the profitability of entry but also on the possibility of entry. The possibility of entry is determined by barriers to entry existing in the market. The consequential key question of 'what is understood by barriers to entry' has been assessed by many economists, however, without reaching an agreement on an overarching concept of barriers to entry.

The first influential concept of barriers to entry was developed by Bain (1956: 3). He defines the term commonly as "an advantage of established sellers in an industry over potential entrant sellers, which is reflected in the extent to which established sellers can persistently raise their price above competitive levels without attracting new firms to enter

13 Following ICN (2006: 41ff.), factors which help to understand the competitive constraints existent in the market include low barriers to entry or expansion, buyer power, the nature of competition in the market, responsiveness of competitors, existence of alternative suppliers or the elimination of a potential competitor.

14 See Scherer and Ross (1990: 533ff.) and Schumacher (1991) for supporting empirical evidence of the seller market power-reducing effect of countervailing buying power.

15 Sunk costs of entry are generally defined as costs which must be incurred to enter a market but which are not recoverable upon exiting the market. 
the industry".16 Stigler (1968) prefers a narrower definition. He proposes to think of a barrier to entry as "a cost of producing (at some or every rate of output) ... which must be borne by a firm which seeks to enter an industry but is not borne by firms already in the industry". Fisher (1979: 23), however, bases his proposal on social welfare when he argues that "[a] barrier to entry exists when entry would be socially beneficial but is somehow prevented ... The social benefit-cost calculation is not correctly reflected in the private benefit-cost calculation of the potential entrant".

Without wanting to enter into an in-depth discussion of the exact implications of the different definitions (see Waterson, 1981; McAfee et al., 2004), it is apparent that Bain's concept considers all factors as barriers to entry which increase an entrant's costs of producing and selling (or which reduce its revenues), while Stigler is only interested in factors that raise an entrant's costs relative to those experienced by the incumbent firms (see ABA, 2005: 122). As a consequence, while the Bainian definition considers scale economies, product differentiation, absolute cost advantages and capital requirements as classical entry barriers, the Stiglerian definition typically does not. Under the latter, scale economies are not an entry barrier as long as entrants and incumbents have equal access to the respective production technologies. ${ }^{17}$

Inspired by the significant differences in the application of these definitions, McAfee et al. (2004) proposed a new taxonomy of barriers to entry. The authors argue that the classical concepts à la Bain, Stigler and others typically aim at studying industry competition in the long run. Antitrust policy makers and consumers are more concerned, however, about the effects in the medium and the short run (see McAfee and Mialon, 2004: 6). McAfee et al. (2004) thus propose to differentiate between economic barriers to entry and antitrust barriers to entry. Economic barriers to entry are defined narrowly in Stiglerian terms, while an antitrust barrier to entry is defined as "a cost that delays entry, and thereby reduces social welfare relative to immediate but equally costly entry" (McAfee and Mialon, 2004: 4). Based on this definition, the authors argue that economies of scale could be an antitrust barrier to entry (albeit no economic barrier to entry) because they can delay entry and therefore can reduce social welfare (see McAfee et al., 2004: 464).

The question of how to measure entry barriers in practical antitrust policy was investigated in depth by NERA (2004: 10ff.), who proposes to measure the following entry barrier indicators:

- Advertising ratio to sales - aims at capturing the level of advertising which a potential entrant must pay to enter the market,

- R\&D expenditure ratio to sales - aims at capturing the level of $R \& D$ expenditure a potential entrant must invest to enter and compete in the market,

- Minimum efficient scale - aims at capturing how large a production facility has to be in order to be able to compete on price with the incumbent firms,

16 See McAfee et al. (2004) for a discussion of different definitions of barriers to entry. The sources of Bainian barriers to entry are diverse and reach from legal entry barriers (such as entry regulation by the state) to several forms of private entry barriers. Private entry barriers are typically subdivided into structural and strategic barriers to entry. Structural barriers to entry are related to structural or technical characteristics of an industry (e.g., economies of scale, absolute cost advantages such as favourable access to raw materials or a favourable geographic location, capital cost requirements, product differentiation advantages, etc.). Strategic barriers to entry are largely based on the notion of strategic entry deterrence, realising that existing firms might deliberately behave in ways that decrease the probability of entry of other firms (see Waldman and Jensen, 2000: 129, and chapter 3 below).

17 As commented by von Weizsäcker (2004), the determination of a suitable definition of barrier to entry crucially depends on the underlying concept of competition. Viewed from that angle, the differences in the definitions between Bain - belonging to the Harvard school and influenced by the structure-conductperformance paradigm - and Stigler - belonging to the Chicago school of antitrust analysis - should not be too surprising, as they are driven by the fundamentally different concepts of competition. 
- Excess industry capacity - aims at capturing the possibility of incumbents to flood the market in the event of entry,

- Firm entry/exit rates - aims at capturing the fact that the presence of sunk costs deters entry and postpones exit,

- Ratio of capital expenditure to sales - aims at capturing the fact that the greater the capital investment that must be financed for any return, the higher will be the hurdle of raising finance,

- Regulatory/Licence restrictions - aims at capturing the fact that new entrants may be barred from entering a market by virtue of government regulation.

The NERA report quantifies these ratios for various industries in the United Kingdom, affording a decent picture of the 'ease of entry' in these industries. However, the list should be considered only as a starting point for developing 'bespoke' indicators covering the specifics of the industry of interest. 18

In addition to assessing the likelihood of entry, the timeliness of entry criterion examines "whether entry would be sufficiently swift and sustained to deter or defeat the exercise of market power" (EU Horizontal Merger Guidelines, Section VI, No. 74). Typically, entry is considered timely if it could occur within two years (from initial planning to significant market impact). However, the time period considered appropriate depends on the characteristics and dynamics of the market as well as on the specific capabilities of the potential entrants (see Oxera, 2006). The analysis of the frequency and successfulness of historical entry episodes in the respective industries may help to assess whether 'timely entry' is likely to be expected (see ABA, 2005: 137ff.).

Finally, the sufficiency of entry criterion demands that entry must be of sufficient scope and magnitude to restrict the exercise of market power. Following the EU Horizontal Merger Guidelines (Section VI; No.75), even rapid and profitable entry might not be sufficient to defeat competitive concerns if entry is, for instance, small-scale and takes place into a market niche. Oxera (2006) proposes to concentrate an assessment of the sufficiency of entry on the general strength of potential entrants, in particular their ability to constrain incumbents' prices.

\subsection{Estimation of the effect of possible merger efficiencies on the post-merger price}

The third step in the detection approach for anticompetitive horizontal mergers considers merger efficiencies. Generally speaking, merger-specific efficiencies are of interest because they have the potential to offset the merged firms' incentives to increase price post-merger. In other words, even if the first two stages of the detection framework come to the conclusion that the merged entity would have the incentive and the possibility to increase price, the existence of merger-specific efficiencies could offset this increase or could even incentivise the merged entity to increase production post-merger.

The follow-up question of what degree of merger efficiencies is sufficient to restore premerger prices can again be estimated by rather simple formulas. In a homogenous Cournot world, the sufficient percentage cost reduction to restore pre-merger prices, $\bar{c}$, can be expressed as a function of the merging firms' market shares and the market demand elasticity (see Annex 7.3 for the proof):

18

The empirical literature has developed so-called 'indices of entry barriers' (see, e.g., Orr, 1974), which include other indicators such as risk (measured as the standard deviation of industry profit rates), past rate of growth in the industry and past profit growth in the industry. 


$$
\bar{c}=\frac{2 s_{j} s_{k}}{\varepsilon_{D}^{m}\left(s_{j}+s_{k}\right)-\left(s_{j}^{2}+s_{k}^{2}\right)},
$$

with $s_{j}$ and $s_{k}$ representing the output-based market shares of the two merging firms. ${ }^{19}$ Plotting Equation (7) for the purpose of an easier interpretation leads to Figure 4 below.

Fig. 4. Sufficient percentage cost reduction to restore pre-merger prices in a homogenous product merger

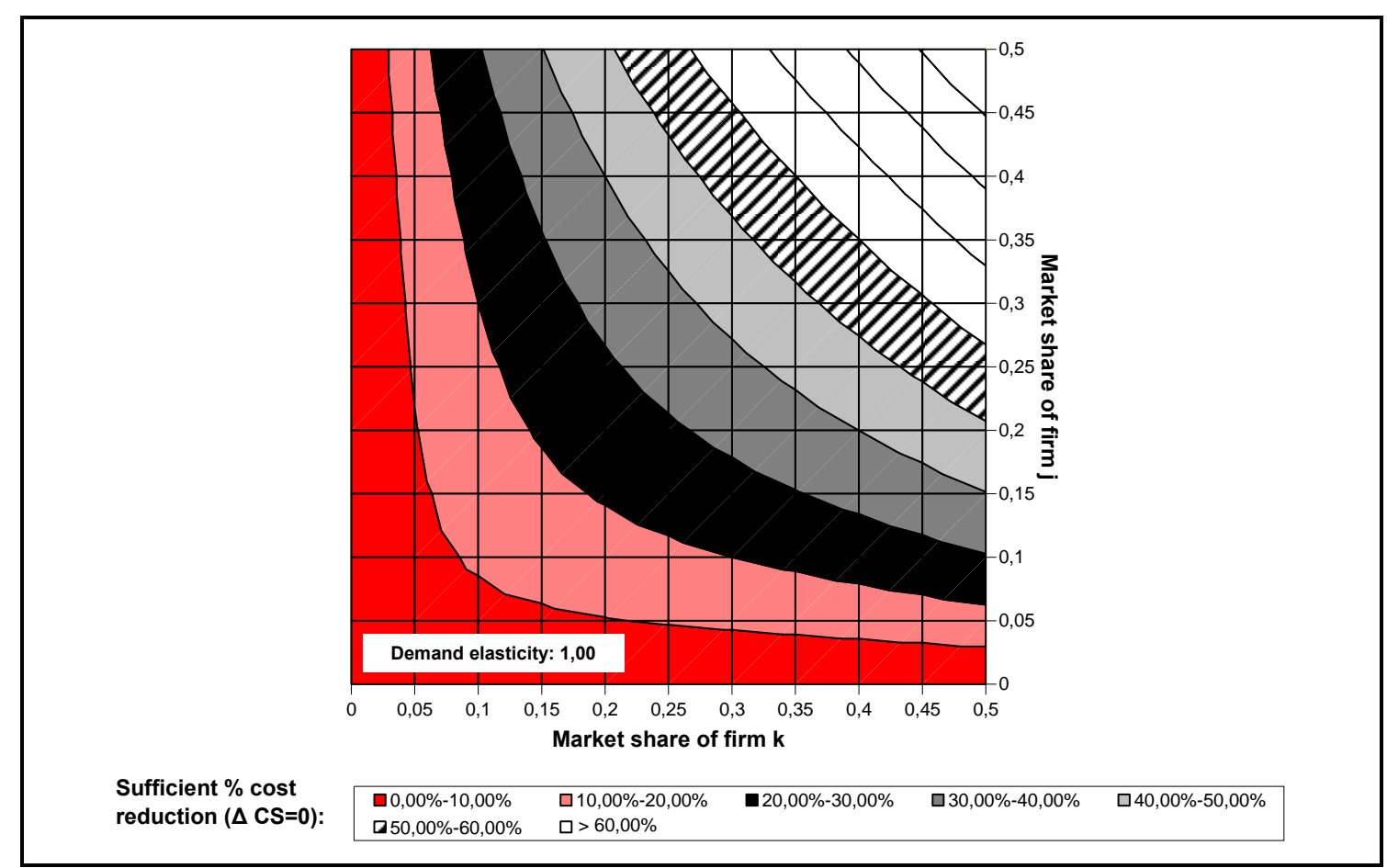

As shown in Figure 4, the sufficient percentage cost reduction rises with the market shares of the two merging firms. In general, even mergers between firms with relatively low market shares have to realise substantial efficiencies in order to restore pre-merger prices. For example, if both firms have a market share of $10 \%$, the respective sufficient cost reduction would be in a range between $10,00 \%$ and $20,00 \%$ (the exact value is $11,11 \%$ ).

However, it has to be kept in mind that Figure 5 is based on unity market demand elasticity. The sensitivity of the sufficient percentage cost reduction with respect to the market demand elasticity is clarified by Table 3 below.

19 In case of symmetric market shares, $\mathrm{s}_{\mathrm{j}}=\mathrm{s}_{\mathrm{k}}=\mathrm{s}$, (24) above simplifies to

$$
\overline{\mathrm{c}}=\frac{2 \mathrm{~s}^{2}}{\varepsilon_{\mathrm{D}}^{\mathrm{m}} \cdot 2 \mathrm{~s}-2 \mathrm{~s}^{2}}=\frac{\mathrm{s}}{\varepsilon_{\mathrm{D}}^{\mathrm{m}}-\mathrm{s}} \text {. }
$$


Table 3. Percentage marginal cost reduction that restores pre-merger price dependent on the change in HHI and demand elasticity

\begin{tabular}{cc|c|ccc}
\hline \multicolumn{2}{c|}{ Market shares of merging } & 'Delta & \multicolumn{3}{c}{ Elasticity } \\
firms & $\mathrm{s}_{\mathrm{k}}$ & $\Delta \mathrm{HHI}$ & 1 & 2 & 3 \\
\hline 0,05 & 0,05 & 50 & $5,26 \%$ & $2,56 \%$ & $1,69 \%$ \\
0,05 & 0,1 & 100 & $7,27 \%$ & $3,48 \%$ & $2,29 \%$ \\
0,1 & 0,1 & 200 & $11,11 \%$ & $5,26 \%$ & $3,45 \%$ \\
0,1 & 0,15 & 300 & $13,79 \%$ & $6,42 \%$ & $4,18 \%$ \\
0,15 & 0,15 & 450 & $17,65 \%$ & $8,11 \%$ & $5,26 \%$ \\
0,2 & 0,2 & 800 & $25,00 \%$ & $11,11 \%$ & $7,14 \%$ \\
0,3 & 0,3 & 1800 & $42,86 \%$ & $17,65 \%$ & $11,11 \%$ \\
0,35 & 0,3 & 2100 & $48,00 \%$ & $19,31 \%$ & $12,09 \%$ \\
0,4 & 0,4 & 3200 & $66,67 \%$ & $25,00 \%$ & $15,38 \%$ \\
0,5 & 0,5 & 5000 & $100,00 \%$ & $33,33 \%$ & $20,00 \%$ \\
\hline
\end{tabular}

Source: Inspired by a comparable table in Froeb and Werden (1998: 269)

As shown in Table 3, estimating the correct market demand elasticity is crucial with respect to the choice of the appropriate marginal cost reduction. A merger between two firms with a $10 \%$ pre-merger market share would demand a percentage marginal cost reduction of $11,11 \%$ for a demand elasticity of 1 , but only a reduction of $5,26 \%$ if the demand elasticity is 2 . Table 3 further shows the respective change in the HHI (or 'delta') value, which can be calculated by doubling the product of the market shares of the two merging companies and multiplying in with 10.000. For example, a merger which leads to a delta of 50 needs to realise a marginal cost reduction of $5,26 \%$ (if unity elasticity is assumed) in order to restore pre-merger prices.

For the case of a differentiated Bertrand model, it is also possible to derive the complementary back-of-the-envelope formula to estimate the sufficient percentage cost reduction which restores pre-merger prices (see Annex 7.4 for the proof):

$$
\bar{c}_{i}=\frac{M_{i} D_{i j} D_{j i}+M_{j} D_{j i} p_{j} / p_{i}}{\left(1-M_{i}\right)\left(1-D_{i j} D_{j i}\right)} .
$$

For the symmetric case, $\mathrm{M}_{\mathrm{i}}=\mathrm{M}_{\mathrm{j}}=\mathrm{M}$ and $\mathrm{D}_{\mathrm{i}}=\mathrm{D}_{\mathrm{j}}=\mathrm{D}$, Equation (8) simplifies to ${ }^{20}$

$$
\bar{c}=\frac{M}{1-M} \frac{D}{1-D} \text {. }
$$

As shown by Equation (9), estimates of the pre-merger price-cost margin and the diversion ratio are enough to receive an estimate of the sufficient percentage cost reduction. Plotting Equation (9) for the purpose of an easier interpretation leads to Figure 5 below.

As reflected in Figure 5 and also stressed by Werden (1996), if the products are relatively differentiated (i.e., $\mathrm{M}$ is high) and the merging firms compete intensively (i.e., D is high), large cost reductions are necessary to restore pre-merger prices. As shown in Figure 5, if the pre-merger price-cost margin is 0,45 and the diversion ratio is 0,3 , the sufficient percentage cost reduction lies between $30,00 \%$ and $40,00 \%$ (the exact value is $35,06 \%$ ).

20 As shown by Werden and Froeb (2007: 15), Equation (9) can also be expressed as a proportion of premerger price leading to $\mathrm{MD} /(1-\mathrm{D})$. 
Fig. 5. Sufficient percentage cost reduction to restore pre-merger prices in a differentiated products merger

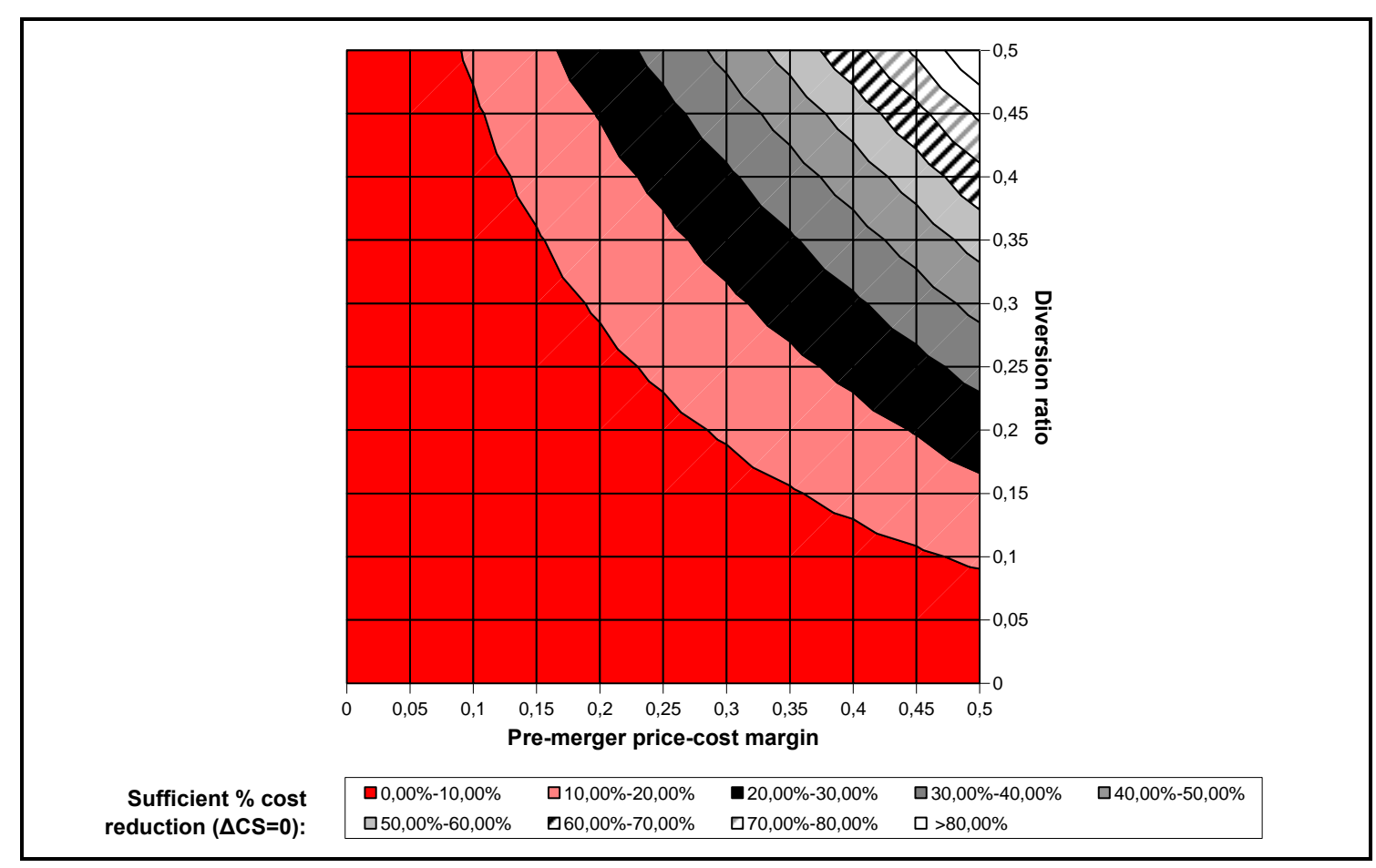

Although the calculation of sufficient percentage cost reductions can be a helpful quantitative tool in assessing merger efficiencies, it masks several important conceptual challenges of merger efficiencies. One general aspect refers to the fact that merger efficiencies do not necessarily have to cause a measurable reduction in marginal cost as it was assumed so far. In practice, merger efficiencies can take many forms, and it is with the antitrust authority to decide which efficiencies are accepted and which are not. Ivaldi et al. (2003: 63), for instance, differentiate between efficiencies generated by a better exploitation of tangible assets (such as rationalisation through the reallocation of the production, exploitation of economies of scale and scope or investment) and those by a better exploitation of intangible assets (such as sharing of know-how, management, R\&D and innovation, product-line redefinition or purchasing power). 21

Given this enumeration, it is straightforward to see that some efficiencies may translate directly into marginal cost reductions (e.g., economies of scale) while others rather lead to a reduction in fixed costs (e.g., R\&D expenditures). The question whether only the former or both types of efficiencies are considered within a merger efficiencies assessment finally depends on the underlying welfare approach followed by the respective antitrust authority. ${ }^{22}$ Additionally, the mentioned efficiencies differ with respect to the time window

21 Evans and Padilla (2003) point out that every merger efficiencies assessment has to consider supply-side efficiencies (referring to the cheaper production of existing products) and demand-side efficiencies (referring to new or better products, such as increased network size or product quality), both which may be realised by a horizontal merger. Kolaski and Dick (2002) provide a taxonomy of possible efficiencies based on the traditional differentiation between allocative efficiencies, productive efficiencies, dynamic efficiencies and transactional efficiencies. As assessed in more detail in Röller et al. (2001: 42ff.), several alternative typologies exist. Röller et al. (2001) differentiate between a typology based on the concept of the production function (rationalisation, economies of scale, technological progress, purchasing economies and slack) and one based on the alternate distinctions of real cost savings vs. redistributive (or pecuniary) cost savings, fixed costs vs. variable costs, firm-level efficiencies vs. industry-level efficiencies and, finally, efficiencies in the relevant market vs. efficiencies in other markets.

22 In general, microeconomic theory suggests that marginal cost savings have a direct influence on shortterm pricing behaviour, while fixed cost savings don't have this influence and would therefore not be 
in which they are scheduled to materialise. For example, while a re-allocation of production can be accomplished fairly quickly, efficiencies in R\&D might only materialise in the medium or long term by, for instance, improving new product development.

In principle, it is possible to weight all these pro- and anticompetitive aspects by a simple calculation of the net present value of the likely benefits and harms of a proposed merger. Simons (2004), for instance, takes a potential merger of two widget producers and assumes that the market investigations of the antitrust authority have revealed the following: the market is widgets with a $80 \%$ probability; entry will not occur for 2 years with a $80 \%$ probability; the anticompetitive effect of the merger is a $10 \%$ price rise for 2 years with a $80 \%$ probability; marginal cost will decline and impact price by $2 \%$ with $70 \%$ probability beginning in year 2 and continuing though year 5; pecuniary costs will decline and impact price by $1 \%$ with $70 \%$ probability beginning in year and continuing through year 5 ; and fixed costs will decline and impact price by $1 \%$ with $70 \%$ probability beginning in year 3 through year 5 . Based on these assumptions, it is possible to calculate the net present value resulting from the proposed merger. This schedule is shown in Table 4 below.

Table 4. Calculating the consumer welfare net present value

\begin{tabular}{|c|c|c|c|c|c|c|c|c|}
\hline & \multirow{2}{*}{$\begin{array}{l}\text { Proba- } \\
\text { bility }\end{array}$} & \multirow{2}{*}{$\begin{array}{l}\text { Harm or } \\
\text { Benefit }\end{array}$} & \multirow{2}{*}{$\begin{array}{c}\text { Risk } \\
\text { adjust- } \\
\text { Ment }\end{array}$} & \multicolumn{5}{|c|}{ Years } \\
\hline & & & & 1 & 2 & 3 & 4 & 5 \\
\hline \multicolumn{9}{|l|}{ Competitive effects } \\
\hline Market definition & 0,8 & & & & & & & \\
\hline Entry & 0,8 & & & & & & & \\
\hline Anticompetitive effects & 0,8 & $-10,0$ & & & & & & \\
\hline Total & 0,51 & $-10,0$ & $-5,1$ & $-5,1$ & $-5,1$ & 0 & 0 & 0 \\
\hline \multicolumn{9}{|l|}{ Efficiencies } \\
\hline Marginal cost & 0,7 & 2,0 & 1,4 & 0 & 1,4 & 1,4 & 1,4 & 1,4 \\
\hline Pecuniary benefits & 0,7 & 1,0 & 0,7 & 0,7 & 0,7 & 0,7 & 0,7 & 0,7 \\
\hline Fixed cost benefit & 0,7 & 2,0 & 1,4 & 0 & 0 & 1,4 & 1,4 & 1,4 \\
\hline Total effect & & & & $-4,4$ & $-3,0$ & 3,5 & 3,5 & 3,5 \\
\hline $\begin{array}{l}\text { Net present value@10\% } \\
\text { rate }\end{array}$ & 0,71 & & & & & & & \\
\hline
\end{tabular}

Source: Content follows Simons (2004: 3)

As shown in the simple spreadsheet calculation above, although the hypothetical merger causes a price increase of $10 \%$ for two years, the net effect of the merger on consumer welfare is positive. It further shows that efficiencies realised years after the completion of the merger can contribute substantially to the procompetitive effects of a merger.

Against this background, the major problem for an antitrust authority with respect to merger efficiencies is to check their plausibility, their likelihood of realisation and their likely effects on post-merger competition. ${ }^{23}$ From a microeconomic perspective, it is

considered as efficiencies. However, as virtually all fixed costs become variable by simply increasing the time horizon, this distinction is often not easy to make in terms of efficiencies (see also Carlton, 2007, who argues that many fixed costs are recurring and respective savings can therefore very well translate into lower future costs - which eventually benefit consumers through lower prices). Furthermore, a total welfare standard would still allow taking account of fixed cost savings. Additionally, as remarked by Everett and Ross (2002: 20ff), the often assumed equality of a price standard and a consumer welfare standard is not correct from a theoretical point of view. While a pure price standard would just concentrate on the post-merger price, a consumer welfare standard would also consider non-price influences of the merger such as effects on product choice or product quality.

23 Ivaldi et al. (2003: 64f.) consider ex post reviews of efficiency gains as a way to secure them for the consumers. Although theoretically appealing, they conclude that it seems illusory to believe that such interventions could be a realistic option for antitrust policy. Davies et al. (2007: IX) report that firms 
straightforward to identify substantial informational advantages on the side of the merging firms about the existence and size of merger remedies. Amir et al. (2004) manage to show in a Cournot oligopoly context that firms have an incentive to 'overestimate' the efficiencies achieved by the merger with respect to both the antitrust authority (in order to get the merger through) and rivals (in order to influence their beliefs on the competitiveness of the new merged entity). They therefore conclude that antitrust authorities should be reluctant to accept cost-reducing arguments, as there is a high probability that the estimated efficiencies are smaller or even non-existent, leading to higher prices in the post-merger world. The results of the majority of empirical studies which tend to show a very moderate successfulness of horizontal mergers - would also (indirectly) support such an argument. As a consequence, antitrust scholars such as Farrell and Katz (2006) have argued that it may be optimal to follow a pure consumer welfare approach in merger control as some kind of counterweight to the firm's informational advantages and to possible lobbying activities during the merger control procedure (see Neven and Röller, 2006). Kaplow and Shapiro (2007: 89) add a dynamic perspective, remarking that "if the process of competition itself ... is of some value, but this value is difficult to measure, it makes sense to tilt the balance against concentration. This might be done by making the threshold for challenge lower ... or through other means, such as being less generous in considering efficiencies in justifying otherwise problematic mergers".

The question of an appropriate standard for 'acceptable' merger efficiencies is - among others - assessed by Farrell and Shapiro (2001). Having in mind their own theoretical finding that not just a reallocation of production but real merger synergies - that is, the integration of specific and hard-to-trade assets which create output/cost configurations which would not be feasible otherwise - are necessary ${ }^{24}$ to avoid welfare-reducing horizontal mergers, they propose a simple, three-step decision tree to extract mergerspecific synergies. The first stage of the framework investigates whether the merged entity would likely achieve the claimed efficiencies. Given the fact that every merger purports to be motivated by substantial efficiencies, an antitrust investigation has to assess whether such calculations are sound and plausible. If this is found to be the case, the second step asks whether the merging firms would likely achieve the efficiencies unilaterally. This question tries to find out whether the efficiencies are merger-specific or not. If this is found to be the case, it is asked in a third step whether the efficiencies could be achieved unilaterally. Only if such a question is denied, then the merger-specific efficiencies are synergies and therefore relevant for an antitrust assessment following the Farrell-Shapiro approach. ${ }^{25}$ Applying the framework would, for instance, allow the conclusion that economies of scale are typically not accepted as synergies, because they can be achieved unilaterally by 'simply' extending the production capacities ${ }^{26}$ (see Farrell and Shapiro, 2001, for a discussion of additional implications).

have actually tried in merger control cases to get the merger through by signing a guarantee that prices will be reduced post-merger. However, the antitrust authorities have been hesitant to accept such behavioural commitments basically because of the monitoring obligations and the implementation of a reporting system post-merger.

24 The availability of non-synergic efficiencies may be largest in cases of high pre-merger market power and therefore the greatest prospect of further increasing that power. However, intensive competition can be an obstacle in the realisation of particular types of efficiencies (see Farrell and Shapiro, 2001: 709).

25 See European Commission (2001) as well as de la Mano (2002) for an extensive discussion of the efficiency defense and the European system of merger control, as well as Copenhagen Economics (2006) for a discussion of practical methods to assess efficiency gains.

26 As argued by Slade (2006: 23), merger-related efficiencies are often exaggerated, as most economies of scale and scope in manufacturing occur at plant level and economies in distribution are often tiny, as they typically do not represent a large fraction of total costs. However, Kolaski and Dick (2003: 245) identify three practical reasons why internal expansion can be more costly than a merger. First, firms can 
Based on these general theoretical considerations and on practical experiences (see especially Everett and Ross, 2002, for an overview), three conditions for 'acceptable' merger efficiencies have been identified (see ICN, 2006: 64):

1. Verifiability - Only those efficiencies will be taken into account which have a high probability of realisation within a reasonably short period after completion of the merger. ${ }^{27}$

2. Benefit to consumers - Some share of the expected benefits of the merger efficiencies are likely to be passed on to consumers in the form of lower prices. ${ }^{28}$ Factually, this condition rules out a pure total welfare standard as appropriate for merger control.

3. Merger specificity - The efficiency gains must be merger-specific, that is, they are unlikely to be produced or available absent the merger.

Only efficiencies which satisfy all three conditions should be considered during (or alternatively following) the competitive assessment of a proposed horizontal merger. However, as reported by Scheffman (2004) for the United States, the practical role of efficiencies is more understood as a sort of 'sliding scale', in which the stronger the anticompetitive case, the less weight is given to efficiencies. In other words, there seems to be no weighting of the magnitude of efficiencies against the magnitude of anticompetitive effects as shown in the spreadsheet in Box 13 above.

\subsection{Consideration of the effects of the merger on other competition variables}

The fourth step of the detection framework has to consider the effects of the merger on competition variables other than price and quantity in order to allow an integrated assessment of the pro- or anticompetitiveness of a specific merger. The importance of such an assessment is expressed by several antitrust scholars, who argue that the traditional focus of antitrust analysis on the effects of a merger on market price is entirely static and too simple to understand the true economic motivations and effects behind a certain

often expand their scale faster by a merger than by internal expansion. Second, adding new capacity in a market with constant or declining demand may also create pressures on price, which could make internal expansion unprofitable. Third, the construction of new capacity may create social waste in the form of first duplicating resources and later (probably) closing down capacity.

27 As discussed in more detail in Davies et al. (2007: VIIIf.), the following types of evidence may be helpful in demonstrating efficiencies to the antitrust authority: detailed analysis of the extent and type of cost savings (e.g., on the basis of a business plan and supporting evidence that justifies the planning methods and shows the reasonableness of the applied assumptions), plant- and firm-level accounting statements, internal studies (using recent cost records and other pertinent objective data), strategic plans, data and analysis of past experience, statements of knowledgeable company personnel, bespoke research into customer preferences, market studies regarding future trends and innovation obstacles, management consulting studies or analysis prepared by antitrust-specialised economic consultants and merger simulation.

28 Werden et al. (2005: 4ff.) identify three channels of how merger efficiencies can affect market prices post-merger (the so-called pass-though effect) in differentiated product markets. The most important channel is the direct effect of the reduction in a product's marginal cost on its own price: "A reduction in the marginal cost of any of the merged firm's products causes a reduction in its price by an amount largely determined by the curvature of that product's demand curve. The other two ways in which marginal-cost reductions affect consumer prices relate to the nature of the competitive interaction among differentiated products. When a reduction in the marginal cost of one of the merged firm's products causes a reduction in that product's price, the price reduction causes a shift in the demand curves of the merged firm's other competing products. Consequently, the merged firm adjusts the prices of all the competing products it sells in response to a reduction in marginal cost for any one of those products. In addition, non-merging sellers of competing products adjust their prices in response to the price changes of the merged firm" (Werden et al., 2005: 4). 
merger. ${ }^{29}$ Following Scheffman (1996: 247), " $\left.\mathrm{t}\right]$ he standard industrial organisation analysis of a merger boils the merger down to potential shifts in static cost and demand curves and concentrates on the effects of the merger on short run pricing dynamics. This approach misses the essence of what business strategy, and mergers, in particular, are about."

Hofer and Williams (2005b) agree with the general argument, especially with respect to socalled fast-moving consumer goods (FMCG) markets (such as soft drinks, tobacco or mobile phones), in which the fundamental dimension of competition is not price but marketing and branding. A reduction in competition due to a merger in such industries could therefore take the form of lower levels of marketing expenditure rather than increases in price. ${ }^{30}$

With respect to the role of innovation, Hofer and Williams (2005b) argue that many of the biggest gains to consumers in markets arise from innovation and dynamic aspects of market competition, "and if reductions in competition lead to reductions in innovation, the consequences for consumers can potentially be at least as serious than the effect of a five to ten percent increase in price" (Hofer and Williams (2005b: 7). In other words, the role of advertising in creating new demand and the role of $\mathrm{R} \& \mathrm{D}$ in creating new technological competition can be critical dimensions of competition and need to be considered as a compulsory part of any competition assessment. ${ }^{31}$

With respect to the role of innovation in merger control, Katz and Shelanski (2006) recently presented an integrated approach of this multifaceted relationship by studying the implications of innovation in the complete merger control procedure consisting of market definition, analysis of competitive effects, consideration of efficiencies and remedies. The authors base their assessment on the separation of two effects which need to be considered as part of an extended merger control procedure: An innovation impact criterion - which takes account of the fact that innovation can affect the relationship between the pre-merger marketplace and the post-merger marketplace - and an innovation incentives criterion, which takes account of the fact that innovation itself can be an important dimension of market performance that could be affected by a merger. "To examine the innovation incentives effect, one asks how the change in market structure and competition brought about by a merger will likely affect consumer welfare through effects on the pace or nature of innovation that might reduce costs or that brings new products to market. To examine the innovation impact effect, the situation is reversed. It refers not to how market structure will affect innovation but to how innovation will affect the evolution of market structure and competition. Innovation is a force that could make static measures of market structure unreliable or irrelevant, and the effects of innovation may be highly relevant to whether a

29 On a more general level, characteristics of so-called new-economy industries need to be considered in competition policy assessments (see, for instance, OFT, 2002). Those characteristics include R\&D and intellectual property, network effects, high fixed/sunk costs and low marginal costs, technical complexity, compatibility and standards.

30 As noted by Hofer and Williams (2005b), such a reduction in marketing competition is difficult to evaluate from a welfare perspective, basically because economists haven't come to final conclusions on the general role of marketing. While some argue that marketing is procompetitive and provides the consumers with relevant information on the respective products, others are of the opinion that marketing is just a mechanism for redistributing rents. "Accordingly, a reduction in marketing expenditures could simply be seen as an efficiency of a merger. However, to the extent that marketing expenditures expand market demand and consumer valuation, then a reduction in marketing expenditures could reduce consumer welfare" (Hofer and Williams, 2005b: 6).

31 The increasing importance of innovation concerns in antitrust policy is underpinned by Gilbert (2007: 2ff.). He analysed the mergers challenged by the US antitrust authorities in three periods: 1990 to 1994 , 1995 to 1999 and 2000 to 2003. In these periods the authorities challenged 135, 269 and 108, mergers respectively, of which 4,47 , and 41 respectively mentioned 'innovation' as a reason for the challenge. Expressed in percentages, the importance of innovation effects rose from about $3 \%$ in the first period to about $18 \%$ in the second period, up to $38 \%$ in the third period. 
merger should be challenged and to the kind of remedy antitrust authorities choose to adopt" (Katz and Shelanski, 2006: 14).

From a practical perspective, there are at least two ways in which innovation incentives have played a role in merger control. First, as part of a merger which involves actually existing product markets in which R\&D is one important competition variable such as, for instance, the software industry. Second, alternatively, a merger can take place between companies who are both solely focusing on R\&D and consequently do not sell any product on a product market at the time of the merger. In such a case, the question arises whether the traditional merger control procedure is applicable at all. Focusing on the first group of cases, Gilbert and Sunshine (1995: 595ff.) suggest the following five-step framework to study the effects of a merger on market power in an innovation market: 1.) Identify the overlapping $\mathrm{R} \& \mathrm{D}$ activities of the merging firms; 2.) Identify alternative sources of $\mathrm{R} \& \mathrm{D}$; 3.) Evaluate actual and potential competition from downstream products; 4.) Assess the increase in concentration in $\mathrm{R} \& \mathrm{D}$ and competitive effects on investment in $\mathrm{R} \& \mathrm{D}$ and 5.) Assess R\&D efficiencies.

In a nutshell, given the ex ante indefiniteness of an increase in concentration on the scope and pace of $R \& D$, it is unlikely that $R \& D$ can be evaluated by the same instruments as the effects of mergers on price. The consideration of innovation markets necessarily has to be approached by some kind of rule-of-reason approach, such as the proposal by Gilbert and Sunshine. In any case such an assessment is affected by its forward-looking and hypothetical character.

\section{Conclusion}

An efficient antitrust policy with respect to horizontal mergers needs to consider a 'detection' stage as well as an 'intervention' stage. However, compared to hard core cartel enforcement, the characteristics and requirements of both stages differ considerably. With respect to the 'detection' stage, the basic aim of merger control is typically not to detect the conduct 'merger' as such but rather to assess whether a notified merger would cause significant anticompetitive effects. As a consequence, while (ex-post) cartel enforcement (as well as most other areas of antitrust policy) is backwards oriented aiming at detecting and proving breaches of the cartel ban, merger control needs to look into the future and must develop a picture of the likely competitive effects in case the proposed merger would be allowed.

With respect to the possible competitive effects, a horizontal merger inevitably leads to the loss of a direct competitor in the (relevant) market and is therefore suspicious of leading to price increases. From an economic perspective, there are basically two strands of argument which can both explain such a post-merger price increase potential. On the one hand, the merged entity 'unilaterally' might have incentives to decrease output and increase price given the increase in market power post-merger. On the other hand, post-merger prices may be higher than pre-merger prices because the remaining firms in the postmerger market may find it easier to tacitly or overtly collude.

In addition to the effect on price, horizontal mergers may influence welfare through several other channels such as product repositioning, product variety as well as incentives to innovate. As all these price- and non-price effects might contribute to the overall pro- or anticompetitiveness of a certain merger proposal, they are invariably reflected in the proposed four step approach which was designed to guide the analysis aiming at detecting anticompetitive mergers: 1 . Estimation of the post-merger price increase; 2 . Consideration of evidence whether such a price increase would be sustainable; 3. Estimation of the effect of possible merger efficiencies on the post-merger price; and 4. Consideration of the effects of the merger on competition variables other than price (such as product variety or the incentives to innovate) 
In the first step of the framework, an estimate of the impact of a horizontal merger on the market price needs to be derived. A homogenous Cournot model as well as a differentiated Bertrand model is used to derive back-of-the-envelope formulas which can be applied to estimate the expected percentage price increase post-merger. Subsequent, the second step of the framework has to assess whether the price increase predicted on the first stage would be sustainable post-merger. As simulation tools typically need to abstract from important factors - such as entry or product repositioning of existing rivals - these factors typically have to be assessed qualitatively. The third step of the framework needs to assess, first, whether the merger efficiencies claimed by the merging parties are existent, merger-specific and are likely to materialize post-merger. Second, it needs to be estimated whether the accepted efficiencies are substantial enough to at least hold the pre-merger price level. As in the first step of the framework, the two standard oligopoly models are applied to derive back-of-the-envelope formulas for the percentage cost reduction sufficient to hold the pre-merger price level. Finally, the fourth step of the framework needs to consider the effects of a horizontal merger on other competition variables such as product variety, marketing as well as $\mathrm{R} \& \mathrm{D}$ post-merger which might influence the overall welfare effects of a merger.

Given this proposal to detect anticompetitive mergers, future research will focus on the design of the complementary intervention stage which becomes relevant when the antitrust authority concludes its preliminary analysis on the detection stage with the finding that the anticompetitive effects of a merger dominate the procompetitive effects. However, in contrast to hard core cartel enforcement, it is not the aim of the intervention stage to sanction proposed anticompetitive mergers but to give the respective firms the possibility to resolve the identified competition problems in order to be allowed to proceed with their merger plans. As a consequence, from the viewpoint of the merging parties, merger remedies must have the potential to ('just') restore competition in the relevant market postmerger, however, subject to the conditions that neither the merger-induced efficiencies nor already realised 'pre-merger' efficiencies are reduced or even destroyed by the respective remedies. From the viewpoint of the antitrust authority, the proposed merger remedies (as an intervention instrument) have to be effective in restoring competition in the relevant market post-merger. Only in cases where such remedies cannot be found (or agreed upon with the firms involved), the antitrust authority eventually has to ban the respective merger.

\section{$5 \quad$ Annex}

\subsection{Price effects of mergers in a homogenous Cournot model}

Given the Lerner index of market power for the firm i, it is possible to derive an aggregate index of market power for an industry as a whole. If $\mathrm{L}=\sum_{\mathrm{i}} \mathrm{s}_{\mathrm{i}} \mathrm{L}_{\mathrm{i}}$ we get

$$
L=\sum_{i} \frac{s_{i}^{2}}{\varepsilon_{D}^{m}}=\frac{H H I}{\varepsilon_{D}^{m}} .
$$

Equation (9) basically shows that there is a direct relationship between industry concentration (HHI) and market power (L).

In horizontal merger cases, an important question is how the price changes from $\mathrm{P}_{1}$ (premerger) to $\mathrm{P}_{2}$ (post-merger) when the $\mathrm{HHI}$ changes from $\mathrm{HHI}_{1}$ (pre-merger) to $\mathrm{HHI}_{2}$ (post-merger). Simply applying Equation (9) for the pre-merger as well as post-merger equilibrium leads to the following expressions (see Nelson and Sun, 2001: 953f.): 


$$
\frac{p_{1}-c}{p_{1}}=\frac{H H I_{1}}{\varepsilon_{D}^{m}} \text { and } \quad \frac{p_{2}-c}{p_{2}}=\frac{H H I_{2}}{\varepsilon_{D}^{m}}
$$

Calculating $\mathrm{p}_{1}$ and $\mathrm{p}_{2}$ as a function of $\mathrm{HHI}_{1}$ and $\mathrm{HHI}_{2}$ we get

$$
p_{1}=\frac{\varepsilon_{D}^{m} \cdot c_{1}}{\varepsilon_{D}^{m}-H H I_{1}} \quad \text { and } \quad p_{2}=\frac{\varepsilon_{D}^{m} \cdot c_{2}}{\varepsilon_{D}^{m}-H H I_{2}}
$$

So

$$
\frac{\Delta p}{p}=\frac{p_{2}-p_{1}}{p_{1}}=\frac{p_{2}}{p_{1}}-1=\frac{c_{2}}{c_{1}} \frac{\varepsilon_{D}^{m}-H H I_{1}}{\varepsilon_{D}^{m}-H H I_{2}}-1 .
$$

If it is assumed that there are no cost savings due to the merger (i.e. $c_{1}=c_{2}$ ) we get

$$
\frac{\Delta p}{p}=\frac{\varepsilon_{D}^{m}-H H I_{1}}{\varepsilon_{D}^{m}-H H I_{2}}-1=\frac{H H I_{2}-H H I_{1}}{\varepsilon_{D}^{m}-H H I_{2}}=\frac{\Delta H H I}{\varepsilon_{D}^{m}-H H I_{2}} .
$$

Furthermore, $\mathrm{HHI}_{2}$ can be expressed as follows

$$
H H I_{2}=\sum_{i}\left(s_{i}\right)^{2}-\left(s_{1}\right)^{2}-\left(s_{2}\right)^{2}+\left(s_{1}+s_{2}\right)^{2}=\sum_{i}\left(s_{i}\right)^{2}+2 s_{1} s_{2}
$$

Therefore, the change in the $\mathrm{HHI}$ is given by

$$
\Delta H H I=H H I_{2}-H H I_{1}=2 s_{1} s_{2} .
$$

and Equation (13) can be expressed in terms of market shares as follows

$$
\frac{\Delta p}{p}=\frac{\Delta H H I}{\varepsilon_{D}^{m}-H H I_{\text {postmerger }}}=\frac{2 s_{1} s_{2}}{\varepsilon_{D}^{m}-\left(\sum_{i}\left(s_{i}\right)^{2}+2 s_{1} s_{2}\right)} .
$$

\subsection{Price effects of mergers in a differentiated Bertrand model}

This section aims at deriving Equations (4) and (5) in the main text which can be used as a 'back-of-the-envelope' calculation to get percentage post-merger price increase estimates. The derivation largely follows Shapiro (2004). In general, the following exercise compares the prices set for two products A and B (which are produced by separately owned firms) in a differentiated Bertrand duopoly with the profit-maximising prices for these two products if a single firm controls both products.

For the case of a linear demand function, the demand curves can be written as $q_{1}=a$ $p_{A}+D p_{B}$ and $q_{B}=a-p_{B}+D p_{A}$. The profit of firm $\mathrm{A}$ is then given by

$$
\pi_{A}=\left(p_{A}-c_{A}\right)\left(a-p_{A}+D p_{B}\right) .
$$

Deriving the first order condition with respect to $\mathrm{p}_{\mathrm{A}}$ and rearranging leads to the following best response function for firm A 


$$
p_{A}=\frac{\left(a+D p_{B}+c_{A}\right)}{2} .
$$

Assuming cost symmetry the unique market price can be calculated to

$$
\bar{p}_{A}=\bar{p}_{B}=\bar{p}=\frac{a+c}{2-D} .
$$

The pre-merger price-cost margin is - as usually - given by $\overline{\mathrm{m}}=\frac{\overline{\mathrm{p}}-\mathrm{c}}{\overline{\mathrm{p}}}$. Substituting (19) and some manipulations lead to

$$
\bar{m}=\frac{a-c(1-D)}{a+c} .
$$

The merged company would control both prices and would set $p$ to maximise $(p-c)(a-p+D p)$ and would charge a post-merger (monopoly) price of

$$
p^{*}=\frac{a+c(1-D)}{2(1-D)}
$$

The percentage price increase is given by $\left(\mathrm{p}^{*}-\overline{\mathrm{p}}\right) / \overline{\mathrm{p}}$ which is equal to

$$
\frac{p^{*}-\bar{p}}{\bar{p}}=\frac{\frac{a+c(1-D)}{2(1-D)}-\frac{a+c}{2-D}}{\frac{a+c}{2-D}}
$$

Several algebraic manipulations lead to

$$
\frac{p^{*}-\bar{p}}{\bar{p}}=\frac{D(a-c(1-D))}{2(1-D)(a+c)}
$$

Substituting for $\bar{m}$, Equation (23) can be written as

$$
\frac{p^{\text {Post-merger }}-p^{\text {Pr } e-\text { merger }}}{p^{\text {Pre-merger }}}=\frac{\bar{m} D}{2(1-D)} .
$$

This is the equation used in the main text for a linear demand function.

For a constant elasticity of demand, it is assumed that the elasticity falls from its premerger level of $\varepsilon$ to a post-merger level of $\varepsilon(1-D)$. Applying the usual mark-up $\overline{\mathrm{m}}=1 / \varepsilon$, we get

$$
\frac{\bar{p}-c}{\bar{p}}=\frac{1}{\varepsilon} \text { and } \bar{m}=\frac{1}{\varepsilon} \text { and } \bar{p}=\frac{c}{1-\frac{1}{\varepsilon}}
$$

Furthermore, we can write 


$$
\frac{p^{*}-c}{p^{*}}=m^{*}=\frac{1}{\varepsilon(1-D)}
$$

and

$$
p^{*}=\frac{c}{1-\frac{1}{\varepsilon(1-D)}} .
$$

To receive reasonable results, inequality $\varepsilon(1-D)>1$ must hold. Using (25) this necessary condition can be written as $\mathrm{D}<(1-\overline{\mathrm{m}})$. In other words, the diversion ratio must not be too large - especially if the pre-merger margins are large - to receive economically sensible results. As explained in more detail by Shapiro (2004: 4) this is another proof that the assumption of constant elasticity of demand cannot hold up for large price increases and should consequently only be considered for relatively small price increases.

Substituting the above equations, the percentage post-merger price increase is given by

$$
\frac{p^{*}-\bar{p}}{\bar{p}}=\frac{\frac{c}{1-\frac{1}{\varepsilon(1-D)}}-\frac{c}{1-\frac{1}{\varepsilon}}}{\frac{c}{1-\frac{1}{\varepsilon}}} .
$$

Cancelling the $\mathrm{c}$ terms and multiplying it by $\varepsilon(1-D)$ leads to

$$
\frac{p^{*}-\bar{p}}{\bar{p}}=\frac{\frac{1}{\varepsilon(1-D)-1}-\frac{1}{\varepsilon(1-D)-(1-D)}}{\frac{1}{\varepsilon(1-D)-(1-D)}}
$$

Rearranging, multiplying by $(\varepsilon-1)(1-D)$ and collecting terms leads to

$$
\frac{p^{*}-\bar{p}}{\bar{p}}=\frac{(\varepsilon-1)(1-D)}{\varepsilon(1-D)-1}-1 \text {. }
$$

Combining these two terms leads to

$$
\frac{p^{*}-\bar{p}}{\bar{p}}=\frac{D}{\varepsilon(1-D)-1} .
$$

Using Equation (26) above finally leads to

$$
\frac{p^{\text {Post-merger }}-p^{\text {Pr } e-\text { merger }}}{p^{\text {Pr } e-\text { merger }}}=\frac{\bar{m} D}{1-D-\bar{m}} .
$$

This is the equation for an iso-elastic demand function used in chapter 2. Equation (32) only provides economically sensible estimates for $1-\mathrm{D}-\overline{\mathrm{m}}>0$ or $\mathrm{D}<1-\overline{\mathrm{m}}$. This is a relatively tight bound. Furthermore, a comparison of the percentage post-merger price increases show that even for the relatively small margin/diversion ratio values (in which the estimates with an iso-elastic demand curve are economically sensible), the percentage difference between both estimates are substantial. This is shown in Table 5 below. 
Table 5. Difference in percentage price increases between iso-elastic and linear demand

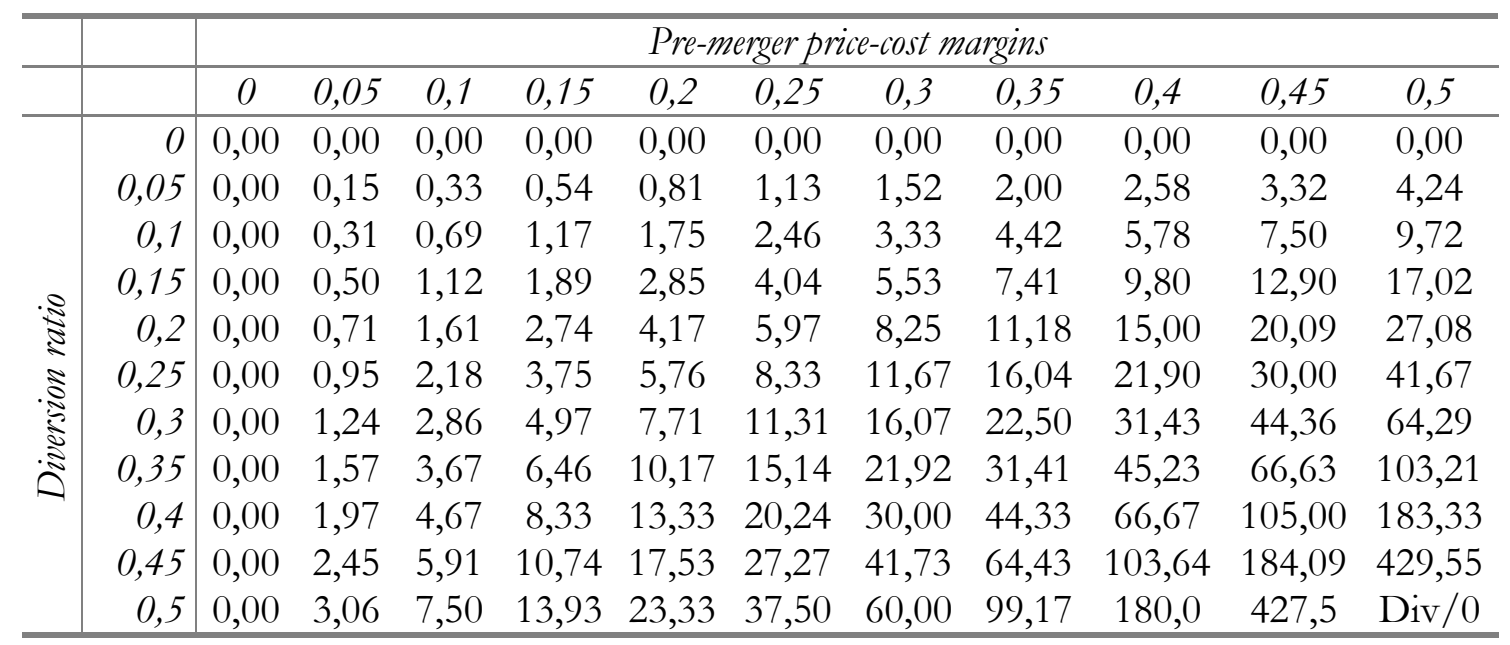

Unit: $\%$ points

As Table 5 shows, even for very small margins and diversion ratios the differences in the percentage price increase estimates between iso-elastic and linear demand functions are quite substantial. In other words, the choice of the correct type of demand function matters in the application of the equations derived above.

\subsection{Sufficient percentage cost reduction to prevent price increases in a homogenous product merger}

In a Cournot model with homogeneous goods, Farrell and Shapiro (1990) showed that without creating substantial synergies, a merger necessarily leads to a reduction in industry output and therefore total welfare. Although the non-merging firms typically react to a decrease in output of the merged firm with an increase in their output, the net effect on total welfare is negative. If, however, a merger in such a Cournot world reduces the marginal costs of the merging firms by a 'sufficient amount', the merging firms have an incentive to increase output post-merger, leading to lower prices and increases in total as well as consumer welfare. The derivation of this 'sufficient amount' (which just leaves consumer surplus unchanged compared to the pre-merger state) is presented below (see generally Froeb and Werden (1998) for the following).

The derivation of the sufficient percentage cost reduction to prevent price increases in a homogenous product merger starts with the well-known first-order condition for profit maximisation in a Cournot model

$$
\frac{p-c_{i}}{p}=\frac{s_{i}}{\varepsilon_{D}^{m}}
$$

with $s_{i}$ being the output-based market share of firm $i$. This equation can be rearranged to

$$
c_{i}=\frac{\left(\varepsilon_{D}^{m}-s_{i}\right) p}{\varepsilon_{D}^{m}} .
$$

Denoting the merging firms with subscripts $j$ and $k$, and substituting the sum of the shares of firms $j$ and $k$ for the merged firm's share lead to the following expression for the merged firm's marginal cost post-merger 


$$
c_{i}=\frac{\left(\varepsilon_{D}^{m}-s_{j}-s_{k}\right) p}{\varepsilon_{D}^{m}} .
$$

The pre-merger (share-weighted) average marginal cost for the merged entity is then given by

$$
c_{i}=\frac{p\left\lfloor s_{j}\left(\varepsilon_{D}^{m}-s_{j}\right)+s_{k}\left(\varepsilon_{D}^{m}-s_{k}\right)\right]}{\varepsilon_{D}^{m}\left(s_{j}+s_{k}\right)} .
$$

The proportionate reduction in marginal cost necessary to restore the pre-merger price can then calculated to

$$
\frac{c_{i}^{0}-c_{i}^{1}}{c_{i}^{0}}=\bar{c}=\frac{2 s_{j} s_{k}}{\varepsilon_{D}^{m}\left(s_{j}+s_{k}\right)-\left(s_{j}^{2}+s_{k}^{2}\right)} .
$$

In the symmetric case, where $s_{j}=s_{k}=s$, Equation (37) simplifies to

$$
\bar{c}=\frac{2 s^{2}}{\varepsilon_{D}^{m} \cdot 2 s-2 s^{2}}=\frac{s}{\varepsilon_{D}^{m}-s} \approx \frac{\left(s_{j} s_{k}\right)^{1 / 2}}{\varepsilon_{D}^{m}-\left(s_{j} s_{k}\right)^{1 / 2}} .
$$

Following Froeb and Werden (1998: 269), substituting the geometric mean of the merging firm's market shares, $\left(\mathrm{s}_{\mathrm{i}} \mathrm{s}_{\mathrm{j}}\right)^{1 / 2}$, provides a good approximation of ' $s$ ' in Equation (38) above and allows the derivation of Table 3 presented in the main text above.

\subsection{Sufficient percentage cost reduction to prevent price increases in a differentiated products merger}

In a Bertrand model with differentiated goods, Deneckere and Davidson (1985) demonstrated that any merger (which generates no cost efficiencies) would lead to price increases for the products of the merging firms and would also incentivise the outsider firms in the market to increase prices for their products. Such a merger would therefore necessarily reduce consumer surplus. If, however, the merger generates sufficient marginal cost reductions for the merging firms, the post-merger equilibrium prices can even undercut the pre-merger equilibrium prices.

To derive the sufficient percentage cost reduction to prevent price increases in a differentiated product merger, it is initially assumed that the merger leaves the market price unchanged, however, reduces marginal costs (see Werden, 1996: 410ff.) for the following). The proportionate reduction in marginal costs can be derived from the usual definition of the price-cost margin $M$ for product $i$. If superscript ' $O$ ' represents pre-merger values and ' 1 ' post-merger values, that definition can be rearranged to

$$
\frac{c_{i}^{0}-c_{i}^{1}}{c_{i}^{0}} \equiv \bar{c}_{i}=\frac{M_{i}^{1}-M_{i}^{0}}{1-M_{i}^{0}} .
$$

Equation (39) can, in turn, be used to derive an expression for the merger-induced cost reduction necessary to restore pre-merger prices. Under the assumption that each product 
is initially sold by a single firm, the pre-merger first-order condition for profit maximisation are

$$
M_{i}^{0}=-1 / \varepsilon_{i i}
$$

and leads to the following condition in case of a two-firm merger that maximises the sum of the profits for the two respective products $i$ and $j$

$$
M_{i}^{1}-M_{j}^{1} D_{j i} p_{j} / p_{i}=-1 / \varepsilon_{i i} .
$$

Equations (40) and (41) can than be solved for the post-merger margins in terms of the pre-merger margins and other quantities

$$
M_{i}^{1}=\frac{M_{i}^{0}+M_{j}^{0} D_{j i} p_{j} / p_{i}}{1-D_{i j} D_{j i}} .
$$

Substituting Equations (40) and (42) into Equation (39) leads to the marginal cost reductions necessary to restore pre-merger prices

$$
\bar{c}=\frac{M_{i} D_{i j} D_{j i}+M_{j} D_{j i} p_{j} / p_{i}}{\left(1-M_{i}\right)\left(1-D_{i j} D_{j i}\right)} .
$$

For the symmetric case, Equation (43) can be simplified to

$$
\bar{c}=\frac{M}{1-M} \frac{D}{1-D} .
$$

This is the equation for the marginal cost reduction necessary to restore pre-merger prices applied in the main text above.

\section{References}

ABA (2005), Market Power Handbook: Competition Law and Economic Foundations, Chicago.

Amir, R., E. Diamantoudi, and L. Xue (2004), Merger Performance under Uncertain Efficiency Gains, Nota di Lavoro 79.2004, Fondazione Eni Enrico Mattei, Venice.

Arrow, K. (1962), Economic Welfare and the Allocation of Resources for Innovation. In: The Rate and Direction of Inventive Activity: Economic and Social Factors, NBER Conference No. 13, Princeton University, Princeton.

Baker, J. (2004), Efficiencies and High Concentration: Heinz Proposes to Acquire BeechNut, in: Kwoka, J. and L. White (Eds.), The Antitrust Revolution, New York, 150-171.

Baker, J. and T. Bresnahan (1985), The Gains from Merger or Collusion in ProductDifferentiated Industries, Journal of Industrial Economics 33, 427-444.

Bishop, S. and M. Walker (2002), The Economics of EC Competition Law, London.

Carlton, D. (2007), Does Antitrust Need to be Modernized?, EAG Discussion Paper 07-3, Washington D.C.

Carlton, D. (2003a), Using Economics to Improve Antitrust Policy, NBER Working Paper, Cambridge.

Carlton, D. and J. Perloff (2000), Modern Industrial Organization, Reading.

Chamberlin, E. (1933), The Theory of Monopolistic Competition, Cambridge.

Copenhagen Economics (2006), Practical Methods to Assess Efficiency Gains in the Context of Article 81(3) of the EC Treaty, Final Report to DG Enterprise and Industry, Copenhagen.

Dahdouh, T. and J. Mongoven (1996), The Shape of Things to Come: Innovation Market Analysis in Merger Cases, Antitrust Law Journal 64, 405-441.

Dansby, R. and R. Willig (1979), Industry Performance Gradient Indexes, American Economic Review 69, 249-60. 
D'Aspremont, C., J. Gabszewicz, and J. Thisse (1979), On Hotelling's ,Stability in Competition', Econometrica 47, 1145-1150.

Davies, J., R. Schlossberg, M. Jaspers, and K. Scholomiti (2007), Efficiencies - A Challenging Horizon in Horizontal Merger Control, in: Global Competition Review (Ed.), Getting the Deal Through - Merger Control 2007, London.

Davis, P. (2006), Coordinated Effects Merger Simulation with Linear Demands, Competition Commission Working Paper, London.

Davis, R. (2003), Innovation Markets and Merger Enforcement: Current Practice in Perspective, Antitrust Law Journal 71, 677-703.

De la Mano, M. (2002), For the Consumer's Sake: The Competitive Effects of Efficiencies in European Merger Control, DG Enterprise Papers No. 11, Brussels.

Deneckere, R. and C. Davidson (1985), Incentives to Form Coalitions with Bertrand Competition, RAND Journal of Economics 16, 473-486.

Diamond, P. and J. Hausman (1994), Contingent Valuation: Is Some Number better than No Number?, Journal of Economic Perspectives 8, 45-64.

Eckbo, E. (1992), Mergers and the Value of Antitrust Deterrence, Journal of Finance 47, 1005-1029.

Eckbo, E. (1989), The Role of Stock Market Studies in Formulating Antitrust Policy Towards Horizontal Mergers, Quarterly Journal of Business and Economics 28, 22-38.

Eckbo, E. (1983), Horizontal Mergers, Collusion and Stockholder Wealth, Journal of Financial Economics 11, 241-273.

Eckbo, E. and P. Wier (1985), Antimerger Policy under the Hart-Scott-Rodino Act: A Reexamination of the Market Power Hypothesis, Journal of Law and Economics 28, 119149.

Epstein, R. (2002), Merger Simulation and Unilateral Effects: A Primer for Antitrust Lawyers, Economics Committee Newsletter 2, 3-6.

Epstein, R. and D. Rubinfeld (2004), Effects of Mergers Involving Differentiated Products, Final Report for DG Competition, Brussels.

Epstein, R. and D. Rubinfeld (2001), Merger Simulation: A Simplified Approach with New Applications, Antitrust Law Journal 69, 883-919.

European Commission (2001), The Efficiency Defense and the European System of Merger Control, European Economy No. 5, Brussels.

Evans, D. and J. Padilla (2003), Demand-side Efficiencies in Merger Control, World Competition 26, 167-193.

Everett, A.-B. and T. Ross (2002), The Treatment of Efficiencies in Merger Review: An International Comparison, Delta Economics Group, Vancouver.

Farrell, J. and M. Katz (2006), The Economics of Welfare Standards in Antitrust, Competition Policy Center, Working Paper CPC-06-061, Berkeley.

Farrell, J. and C. Shapiro (2001), Scale Economies and Synergies in Horizontal Merger Analysis, Antitrust Law Journal 68, 685-710.

Farrell, J. and C. Shapiro (1990), Horizontal Mergers: An Equilibrium Analysis, American Economic Review 80, 107-126.

Froeb, L. and G. Werden (1998), A Robust Test for Consumer Welfare Enhancing Mergers Among Sellers of a Homogeneous Product, Economics Letters 58, 267-269.

Gilbert, R. (2007), Competition and Innovation, Working Paper, University of California, Berkeley.

Gilbert, R. and S. Sunshine (1995), Incorporating Dynamic Efficiency Concerns in Merger Analysis: The Use of Innovation Markets, Antitrust Law Journal 63, 569-601.

Hausman, J. and G. Leonard (2005), Using Merger Simulation Models: Testing the Underlying Assumptions, International Journal of Industrial Organization 23, 693-698.

Hausman, J. and G. Leonard (1997), Economic Analysis of Differentiated Products Mergers Using Real World Data, George Mason Law Review 5, 321-344.

Hausman, J., G. Leonard, and J. Zona (1994), Competitive Analysis with Differentiated Products, Annales d'Economie et de Statistique 34, 159-180.

Hoerner, R. (1995), Innovation Markets: New Wine In Old Bottles?, Antitrust Law Journal 64, 49-73.

Hofer, P. and M. Williams (2005a), Horizontal Merger Assessment in Europe, NERA Bulletin, London.

Hofer, P. and M. Williams (2005b), Minding your Ps and Qs: Moving Beyond Conventional Theory to Capture the Non-Price Dimensions of Market Competition, NERA Antitrust Insights, London.

Hüschelrath, K. (2008), Competition Policy Analysis. An Integrated Approach, forthcoming Physica Publishing, Heidelberg. 
ICN (2006), Merger Guidelines Workbook, ICN Merger Working Group: Investigation and Analysis Subgroup, Prepared for the Fifth Annual ICN Conference, Cape Town.

Ivaldi, M., B. Jullien, P. Rey, P. Seabright, and J. Tirole (2003), The Economics of Tacit Collusion, Final Report for DG Competition, Toulouse.

Kaplow, L. and C. Shapiro (2007), Antitrust, Working Paper, Harvard University, Cambridge.

Katz, M. and C. Shelanski (2006), Mergers and Innovation, Working Paper, University of California, Berkeley.

Kolaski, W. and A. Dick (2002), The Merger Guidelines and the Integration of Efficiencies into Antitrust Review of Horizontal Mergers, Antitrust Law Journal 71, 207-251.

McAfee, P. and M. Williams (1988), Can Event Studies Detect Anticompetitive Mergers?, Economic Letters 28, 199-203.

Kreps, D. and J. Scheinkman (1983), Cournot Precommitment and Bertrand Competition yield Cournot Outcomes, Bell Journal of Economics 14, 326-337.

Nelson, P. and S. Sun (2001), Consumer Savings from Merger Enforcement: A Review of the Antitrust Agencies' Estimates, Antitrust Law Journal 69, 921-954.

Neven, D. and L.-H. Röller (2006), Consumer Surplus vs. Welfare Standard in a Political Economy Model of Merger Control, International Journal of Industrial Organization 23, 829848.

Office of Fair Trading (2002), The Development of Targets for Consumer Savings Arising from Competition Policy, Economic Discussion Paper 4, London.

Rapp, R. (2004), Antitrust \& Innovation, The Milken Institute Review, Third Quarter 2004, $14-$ 23.

Robinson, J. (1933), The Economics of Imperfect Competition, London.

Röller, L.-H., Stennek, J. and F. Verboven, F. (2001), Efficiency Gains from Mergers, in: European Commission, The Efficiency Defence and the European System of Merger Control, European Economy No. 5, Brussels, 31-127.

Scheffman, D. (1996), Antitrust, Economics and "Reality", in Coate, M. and A. Kleit (Eds.), The Economics of the Antitrust Process, Amsterdam, 239-254.

Scheffman, D. (2004), Efficiencies-Dynamic Analysis-Integrated Analysis, LECG Presentation, Boston.

Scherer, F. (1996), Industry Structure, Strategy, and Public Policy, New York.

Schumacher, U. (1991), Buyer Structure and Seller Performance in U.S. Manufacturing Industries, Review of Economics and Statistics 73, 277-284.

Schumpeter, J. (1942), Capitalism, Socialism, and Democracy, New York.

Shapiro, C. (2004), Unilateral Effects Calculations, Working Paper, University of California, Berkeley.

Shapiro, C. (1995), Mergers with Differentiated Products, Speech Manuscript, U.S. Department of Justice, Washington D.C.

Simons, J. (2004), Unified Merger Analysis: Integrating Anticompetitive Effects and Efficiencies, and Emphasizing First Principles, Working Paper, Washington D.C.

Slade, M. (2006), Merger Simulations of Unilateral Effects: What Can we Learn from the UK Brewing Industry?, Working Paper, University of Warwick, Coventry.

Stillman, R. (1983), Examining Antitrust Policy towards Horizontal Mergers, Journal of Financial Economics 11, 225-240.

Wald, D. and D. Feinstein (2004), Merger Enforcement in Innovation Markets: The Latest Chapter - Genzyme/Novazyme, Antitrust Source, July 2004, 1-11.

Walker, M. (2005), Merger Simulation Models: Useful or Just Dangerous?, Working Paper, Charles River Associates, London.

Werden, G. (2004b), A Daubert Discipline for Merger Simulation, Presentation at the FTC Merger Enforcement Workshop, Washington D.C.

Werden, G. (1996), A Robust Test for Consumer Welfare Enhancing Mergers among Sellers of Differentiated Products, Journal of Industrial Economics 44, 409-413.

Werden, G. and L. Froeb (2007), Unilateral Competitive Effects of Horizontal Mergers, Working Paper, Washington D.C.

Werden, G., L. Froeb, and S. Tschantz (2005), Incentive Contracts as Merger Remedies, Working Paper 05-27, Vanderbilt University Law School, Nashville.

Whinston, M. (2006), Lectures on Antitrust Economics, Cambridge.

Widnell, N. (1996), The Crystal Ball of Innovation Market Analysis, George Mason Law Review 4, 369-403.

Willig, R. (1991), Merger Analysis, Industrial Organization Theory, and Merger Guidelines, Brookings Papers: Microeconomics 1991, 281-332. 